\title{
A IMUNIDADE NA FEBRE TIFOIDE. II. ANTIGENOS E RESPOSTA IMUNE NAS SALMONELOSES SISTEMICAS
}

\author{
ARLETE MOREIRA MILHOMEM* \\ ITTALO SUASSUNA**
}

Os resultados dos trabalhos acumulados a partir do in icio do século permitem concluir que, apesar de numerosos progressos e estudos dos pontos de vista quimico, imunoquímico, genético e biológico, o(s) antigeno(s) responsável( is) pela imunidade nas salmoneloses sistêmicas ainda não está( $\tilde{a}$ o) definido(s).

As mais diversas preparaçōes têm sido propostas como possiveis imunógenos, bem como uma ampla variedade de modelos experimentais e de métodos de avaliaçāo da resposta imune. Em relação ao primeiro aspecto, sendo a Salmonella typhi, em condiçōes naturais, um patógeno exclusivo do homem, os resultados obtidos em animais de laboratório freqüentemen te não se correlacionaram com os obtidos em seres humanos.

Salienta-se que a pesquisa da resposta imune tem sido limitada na maoria das vezes à avaliação do titulo de aglutininas para os antigenos $\mathrm{O}, \mathrm{He} \mathrm{Vi}$; ou a testes de proteção passiva ou ativa em camundongos.

A imunidade celular tem sido definida, principalmente por testes cutâneos, com preparaçōes de natureza protéica, de composiçāo variável e estrutura química mal-definida.

Todos os dados revistos levam à conclusão de que até o presente, ignora-se o, ou os mecanismos de imunoproteção nas salmoneloses sistêmicas.

Até o presente, a antígeno ou antígenos implicados na proteção oferecida por vacinas antitifoídicas é objeto de discussōes (Milhomem \& Suassuna, 1982).

Alguns destes antígenos foram reconhecidos desde o início do século, e suas localizações na parede celular, suas propriedades sorológicas, seus efeitos biológicos e impli-

\footnotetext{
*Trabalho do Departamento de Microbiologia Médica, Instituto de Microbiologia, Universidade Federal do Rio de Janeiro, R.J. Parte de tese para obtenção do título de Doutor, com auxílio do CNPq, CAPES E FINEP.

* Faculdade de Ciências Médicas, Universidade do Estado do Rio de Janeiro. Av. 28 de Setembro, 87 - 20551 Rio de Janeiro, RJ, Brasil.
}

Recebido para publicação em 26 de agosto e aceito em 14 de setembro de 1982. 
cações clínicas intensamente investigados. Mais recentemente, suas estruturas químicas, a biossintese e os determinantes genéticos têm sido objeto de intensa pesquisa.

O papel dos componentes antigênicos destes microrganismos, na virulência e na imunidade para salmoneloses sistêmicas será a seguir sumariamente discutido.

\section{Antigeno $H$}

$\mathrm{O}$ antígeno $\mathrm{H}$ teve sua participação enfaticamente negada por Arkwright (1927), quando baseado em testes de proteção ativa em cobaios, demonstrou que vacinas preparadas a partir de amostras lisas davam igual proteção quer tivessem sido aquecidas a $100^{\circ} \mathrm{C}$ ou $53^{\circ} \mathrm{C}$. Estes resultados foram confirmados por Schutze (1930) em camundongos e o ponto de vista de Arkwright (1927) foi reconhecido pela maioria dos investigadores (Apud Raffel, 1953).

No primeiro ensaio de campo controlado, o achado laboratorial que mais se relacionou com a efetividade das vacinas no homem foi a produção em coelhos de aglutininas anti-H (Edsall et al, 1959). Esses autores sugeriram que, ao antígeno $\mathrm{H}$, não havia sido dada a devida importância como possível fator de proteção. Esta observação levou alguns investigadores a reexaminarem a influência do antígeno nos mecanismos patogênicos da febre tifóide.

Em publicações posteriores, Tully \& Gaines (1961) relataram que a perda do antígeno flagelar em amostras lisas de $S$. typhi não se associava a uma diminuição da virulência para camundongos. Os mesmos investigadores (Tully, Gaines \& Tigertt, 1963) repetiram as experiências em chimpanzés e reafirmaram não terem encontrado evidência de que o antígeno fosse importante quanto à virulência ou à proteção em infecções experimentais nesses animais. No mesmo ano Biozzi et al (1963) também negaram qualquer ação protetora do antígeno quando observaram que, em camundongos, anticorpos anti-H não apresentavam atividade opsonizante.

Posteriormente Benenson (1964) a Hejfec et al (1966) publicaram que nos resultados de pesquisas de aglutininas no soro dos indivíduos, particularmente em ensaios de campo, de maneira semelhante aos resultados de Edsall et al (1959), observava-se que a imunogenicidade deste ant ígeno parecia ser um atributo das vacinas de melhor correlação com a proteção obtida no homem. Para Benenson (1964), no entanto, as evidências apresentadas por alguns investigadores anteriormente citados, bem como a frequência de recidivas de febre tifóide em indivíduos com elevado título de aglutininas anti-H, faziam com que uma relação entre atividade imunizante destas vacinas e título de aglutininas anti-H, fosse altamente improvável.

A presença deste antígeno nas vacinas antitifoídicas cujas evidências de uma ação proterora eram muito poucas, trazia contudo problemas de diagnóstico sorológico da febre tifóide como salientado por Anderson \& Gunnel (1964). Com base nestas observações os mesmos autores sugeriram que as vacinas antitifoídicas fossem preparadas a partir de uma mutante de amostra Ty 2 não flagelada e denominada de TNMI.

Com esta amostra (TNMI) e a mesma metodologia empregada no preparo da vacina $\mathrm{K}$, foi produzida uma vacina cuja ação foi avaliada em ensaio de campo controlado, realizado no Egito. Os resultados deste ensaio, publicados por Wahdan et al (1975), demonstraram que a vacina, teoricamente idêntica, exceto pela falta de ant ígeno $\mathrm{H}$, à vacina $\mathrm{K}$ utilizada nos outros ensaios, nāo ofereceu proteçao. $\mathrm{O}$ fato observado foi atribuído a outras propriedades imunogênicas que năo a síntese do antígeno $\mathrm{H}$, ausentes na mutante TNMI.

Para Edwards et al (1974) ou as aglutininas anti-H teriam um papel significante na proteção ou fatores do soro ainda não identificados estariam envolvidos. Beumer 
(1974), no entanto, sugeriu que a proteção para o homem seria dada por anticorpos para um ou mais antígenos bacterianos, preservados nas mesmas condições que o ant ígeno $\mathrm{H}$.

\section{Antigeno $\mathrm{Vi}$}

Um outro componente da superfície encontrado em algumas bactérias, cujo papel na virulência e imunidade continua em discussão é o antígeno Vi. Este antígeno foi descoberto por Felix \& Pitt (1934 a,b) os quais tentaram correlacionar a virulência de $S$. typhi, para camundongos com a presença e a quantidade deste antígeno na amostra (1951).

Uma análise dos resultados destes investigadores sobre a importância do antígeno na virulência de $S$. typhi para camundongos e seres humanos, bem como de outros cujos resultados confirmaram ou negaram este papel, foi feita por Spaun (1957). Segundo este, as experiências até então realizađas não justificariam a conclusão de que a patogenicidade dos microrganismos fosse independente da síntese do antígeno $V i$ desde que amostras de bacilos tíficos de elevada patogenicidade, e sem este antígeno, não foram descritas.

Posteriormente o papel do antígeno Vi na virulência foi reexaminado por alguns investigadores, que utlizando, como modelo animal, camundongos (Tully \& Gaines, 1961) ou chimpanzés (Tully, Gaines \& Tigertt, 1962), além do homem (Hornick et al, 1970), encontraram evidências sugestivas de sua participação na virulência.

Este antígeno foi considerado uma substância extremamente lábil à ação do calor e de vários agentes químicos (Felix, 1951; Felix \& Pitt, 1934b) o que levou a modificações nos métodos de preparo das vacinas antitifóídicas.

A termolabilidade deste antígeno, principal objeção ao emprego de vacinas aquecidas, foi contestada desde os estudos iniciais de Felix. Assim é que já Smith (1938) demonstrou ser este antígeno resistente não só à fervura como à autoclavação, bem como relatou a obtenção, em coelhos, de anticorpos anti Vi com extratos aquecidos. Os resultados deste investigador foram confirmados posteriormente (Carlinfanti 1946; Webster, Landy \& Freeman, 1952), e o próprio Felix (1952) admitiu ser este antígeno liberado da célula por aquecimento. Células previamente aquecidas e lavadas liberaram a mesma quantidade de antígeno Vi quando reaquecidas (Stuart, 1956). As experiências de Peluffo (1941) demonstraram que, com células bacterianas previamente liofilizadas, as características imunológicas do antígeno Vi foram mantidas, mesmo após um aquecimento a $150^{\circ} \mathrm{C}$ por uma hora.

$\mathrm{O}$ primeiro investigador a relatar uma separação do ant ígeno Vi de outros componentes bacterianos, como o antígeno 0, foi Ashida (1949). Este investigador purificou o antígeno, a partir de extratos alcalinos de uma preparação tipo Boivin, por precipitação ácida.

Logo após Webster, Landy \& Freeman (1952) introduziram novo método de purificação baseado no fracionamento da extratos bacterianos por etanol em presença de elevada concentração de cloreto de sódio (35\%). Para a remoção de contaminantes somáticos ainda presentes, estes investigadores utilizaram hidrólise por ácido acético à quente. Posteriormente, dois outros métodos foram descritos, nos quais não estiveram envolvidos o uso de álcali, ácido ou aquecimento. O primeiro destes métodos descritos por Baker et al (1959), consistiu no fracionamento de extratos bacterianos por solventes orgânicos (acetona, etanol) e detergente (Brometo de $N$-acetil- $N, N$-trimetil amônio, "Cetavlon"). O segundo método utilizou fracionamento por etanol, eletroforese e hidrólise enzimática (Jarvis, Mesenko \& Kyle, 1960). Um outro método foi descrito por Wong \& Feeley (1972) e consistiu em hidrólise enzimática e fracionamento com etanol e detergente ("Cetavlon"). 
As propriedades físico-químicas e imunológicas de antígenos purificados, a partir de amostras de $S$. typhi e Citrobacter freundii (amostra 5396/38) diferiram ligeiramente entre si (Baker et al, 1959; Webster et al, 1954).

De acordo com Edwards \& Ewing (1972) através de imunoeletroforese foi verificado que o antígeno Vi de $S$. typhi consistia de 6 fraçōes, das quais 2 eram termolábeis e 4 termoestáveis, enquanto que o antígeno Vi de Citrobacter continha as duas frações termolábeis e duas termoestáveis. Já em $S$. paratyphi $C$ este antígeno tinha um comportamento semelhante ao de proteínas, ou seja às duas frações termolábeis de $S$. typhi e Citrobacter. Para estes e outros investigadores (Levin et al, 1975) não há na literatura evidências conclusivas sobre uma identidade imunológica e/ou química entre preparações obtidas de diferentes amostras.

Estudos físico-químicos definiram o antígeno como um polímero de ácido-Nacetil-galactosaminurônico e, quando derivado de Citrobacter, continha grupos 0-acetil. Estes grupos foram removidos em prepraçōes submetidas à hidrólise ácida (Webster, Landy \& Freeman, 1952) ou hidrólise alcalina (Jarvis et al, 1967).

Uma comparação entre preparaçōes obtidas pelo método de Webster, Landy \& Freeman (1952) e o de Jarvis, Mesenko \& Kyle (1960), levou Landy et al (1963) a concluírem que a hidrólise ácida despolimerizava parcialmente o antígeno, levando a modificaçōes físico-químicas e imunológicas. Para camundongos o poder imunogênico e protetor do antígeno contendo grupos 0 -acetil foi cerca de quarenta vezes maior que o obtido com as preparaçōes de Webster, Landy \& Freeman (1952). Posteriormente Martin, Jarvis \& Milner (1967) estudando o efeito da despolimerização da molécula, por tratamento sônico, em relação às suas propriedades físico-químicas e imunológicas, concluíram que, quanto ao último aspecto, as razđes das diferenças encontradas por Landy et al (1963) não puderam ser determinadas.

A importância de anticorpos anti-Vi para proteção de camundongos tem sido defendida por alguns investigadores (Gaines, Currie \& Tully, 1960, 1965; Landy, 1953; Wong \& Feeley, 1972; Wong et al, 1974) e negada por outros (Diena et al, 1973, 1975, 1977; Standfast, 1960).

De acordo com Wong et al (1974), a influência deste antígeno nos mecanismos celulares de defesa não foi investigada. Para Collins (1974), um dos defensores deste mecanismo na imunidade, os resultados favoráveis obtidos em camundongos foram mais influenciados pelas vias de inoculação.

No que diz respeito à proteção humana, os resultados de ensaios de campo com vacinas inativadas com etanol foram insatisfatórios, bem como a imunização de voluntários humanos com antígeno Vi purificado (Hornick et al, 1970). Os resultados insatisfatórios nos voluntários foram atribuídos ao método de purificação do ant ígeno utilizado (Webster, Landy \& Freeman, 1952), uma vez que preparações obtidas a partir de $S$. typhi pelo método de Wong \& Feeley (1972) foram muito mais efetivas para camundongos (Wong et al, 1974).

A influência do ant ígeno 0 nos resultados obtidos para o ant ígeno $\mathrm{Vi}$, foi aceita como uma possibilidade, nāo só em camundongos (Archer \& Whitby, 1957; Spaun, 1957), como em outros modelos experimentais. Em experiências de proteção passiva, em ovos embrionados, Grabar \& Le Minor (1951) concluíram que soro de animais (coelhos) contendo anticorpos anti-0 ou anti-Vi de Citrobacter não protegia ante o desafio por $S$. typhi. De acordo com Carter \& Collins (1977) embora anticorpos para os antígenos 0 e $\mathrm{Vi}$ possam ter um papel na inativação inicial do germe, este é de pouca importância uma vez que, em experiencias onde a via peritoneal foi empregada para imunização e desafio, os resultados favoráveis observados foram decorrentes de fatores inespecíficos. 
Outros investigadores (Eigner et al, 1970) empregando o mesmo modelo experimental, sugeriram a existência em $S$. typhi de um antígeno $\mathrm{X}$ diferente do antígeno $0 \mathrm{e}$ do Vi. Esta mesma designação, ou seja, antígeno X, fora utilizada por Topley \& Ayrton (1924) para descrever um antígeno presente em certos sorotipos de salmonelas. Posteriormente um outro grupo de pesquisadores (Joyeux et al, 1974) relatou que este antígeno era facilmente removido da célula bacteriana com $\mathrm{NaCl} 0,5 \mathrm{M}$ e, não estava presente em preparações purificadas de antígeno Vi. Uma total separação desses antígenos não foi possível por centrifugações diferenciais $(35.000$ e $105.000 \mathrm{~g})$. Os mesmos investigadores descreveram esse antígeno como uma substância de natureza protêica, contaminada com dez por cento de ant ígeno $\mathrm{Vi}$, o qual, quando absorvido, eliminou o poder protetor da fração, pondo em dúvida se este antígeno seria uma substância distinta do antígeno Vi ou uma parte deste, eliminada durante o processo de purificação (Joyeux et al, 1977).

\section{Fimbrias}

No que diz respeito a outros antígenos da superfície bacteriana, o conhecimento de que fímbrias eram essenciais para colonização de certas bactérias, entre elas algumas da família Enterobacteriaceae, abriu novos caminhos em pesquisas sobre proteção contra infeç̧ões bacterianas (Kline, 1976).

Um possível papel de fímbrias como fator de virulência em Salmonella foi pesquisado por Duguid, Anderson \& Campbell (1966) os quais concluíram, baseados na existência de amostras genotipicamente nāo fimbriadas em espécies patogênicas, que as fímbrias não tinham papel importante nas infecçōes causadas por estes microrganismos.

Este fato foi confirmado posteriormente por Tannock, Blumershine \& Savage (1975) quando observaram não haver correlação entre a presença de fímbrias em $S$. typhimurium e sua capacidade de ligar-se e invadir a mucosa do íleo de camundongos.

Um ano mais tarde, Duguid, Darekar \& Wheater (1976), utilizando o mesmo modelo experimental que os investigadores acima referidos, concluíram que, apesar de não serem essenciais para a virulência deste germe, as fímbrias facilitaram o estabelecimento da infecção e do estado de portador, em camundongos inoculados por via oral com $S$. $t y$ phimurium.

De maneira semelhante ao que ocorre com salmonelas, o papel de fímbrias na virulência de shigelas tem sido questionado. Andrade (1979), utilizando como modelo experimental a ceratoconjuntivite de cobaios, demonstrou diferenças significativas na virulência da fase fimbriada de $S$. flexneri em relaçăo à fase não fimbriada.

Os componentes superficiais responsáveis pela aderência de salmonelas à mucosa intestinal não foram ainda definidos (Smith, 1977).

\section{Antigeno 0}

Em relação ao antígeno 0, apesar de numerosas investigações sob o ponto de vista químico, imunoquímico e genético (Luderitz et al, 1971; Osborn, Gander \& Parisi, 1972; Osborn \& Rothfield, 1971; Stocker \& Makela, 1971), o seu papel real na patogenia e/ou na imunidade, das salmoneloses sistêmicas constitui até o presente motivo de discussoes entre todos os investigadores.

Este antígeno constitui parte do lipopolissacarídio (LPS) da parede celular de enterobactérias e é responsável pela especificidade antigênica da molécula.

Para maior facilidade de discussão sobre seu papel na virulência e imunidade das salmoneloses sistêmicas faremos breve descrição de sua estrutura química, que se encontra descrita em numerosos trabalhos e revisōes, entre eles, os de Luderịtz, Staub \& Westphal (1966) e Luderitz et al (1971). 
$\mathrm{O}$ antígeno 0 e as propriedades endotóxicas do LPS estão intimamente associados, embora as estruturas responsáveis pela especificidade antigênica possam ser distinguidas da estrutura responsável pela toxicidade. Uma vez que estas propriedades se encontram em uma mesma molécula, este antígeno é, algumas vezes, denominado de endotoxina.

O primeiro passo na identificação da estrutura dos LPS de enterobactérias consistiu no seu isolamento e na identificação dos monômeros liberados por hidrólise ácida total. A análise qualitativa demonstrou que todas as salmonelas estudadas continham cinco açúcares básicos ou seja: $N$-acetil-glicosamina, galactose, glicose, heptose e ácido 2-ceto-desoxiotulônico (KDO) e que, de acordo conn a composição qualitativa de seus LPS, poderiam ser classificadas em quimiotipos.

A presença destes açúcares comuns em todas as salmonelas levou ao conceito de que nestes LPS a cadeia lateral cuja composição e ligação entre os açúcares determinam sua especificidade sorológica, estava ligada a um lipídio, denominado de lipídio A, responsável pela atividade endotóxica, através destes açúcares comuns também denominados de cerne ("core"). O estudo com mutantes rugosas, bloqueadas na formação ou transferência dos vários componentes do polissacarídio, demonstrou que este cerne apresentava pequenas variaçōes entre as diferentes espécies, nāo só em relação à estrutura química como no relativo à especificidade sorológica. A análise química revelou que, baseando-se no lipopolissacarídio $\mathrm{R}$, as salmonelas poderiam ser classificadas em cinco grupos de acordo com sua composição química. Estes quimiotipos, por conveniência, receberam as denominações de $\mathrm{Ra}, \mathrm{Rb}, \mathrm{Rc}, \mathrm{Rd}$ e $\mathrm{Re}$, ou seja, aquelas contendo respectivamente 5, 4, 3, 2 e 1 açúcares em análise qualitativa. A mutante rugosa Re parece idêntica nos LPS de todas as enterobactérias estudadas até o presente.

Em relação às cadeias responsáveis pela especificidade dos antígenos 0 temos, na maioria dos LPS, uma cadeia lateral constituída de unidades repetidas de oligossacarídios cuja estrutura e composição diferem entre as amostras bacterianas. Em vários ant ígenos 0 esta cadeia lateral é constituída de açúcares ordinários (manose, ramnose, etc.) nas mais diversas combinações, enquanto em outros, açúcares menos comuns (3-6 didesoxi-hexoses) constituem fatores de especificidade sorológica. De acordo com a composiçâo e ligaફ̧ão destes açúcares em unidades repetidas, as salmonelas foram classificadas em grupos sorológicos podendo apresentar um ou mais fatores responsáveis pela especificidade do antígeno 0, cabendo a um deles uma função imunodominante. Estes grupos, de acordo com os determinantes dos antígenos 0 e dos antígenos $\mathrm{H}$, foram subdivididos em tipos sorológicos. Uma vez que neste trabalho foram discutidos problemas ligados não só às salmoneloses sistêmicas do homem, mas ainda àquelas de outros mamíferos, apresentaremos na Tabela I alguns exemplos das salmonelas patogênicas para o homem e outros animais e os fatores que constituem seus antígenos 0 . As diferenças conhecidas nos antígenos 0 dos grupos sorológicos A, B, C e D não explicam o fenômeno da especificidade destas salmonelas por determinado hospedeiro, desde que, como exemplo, no grupo sorológico $\mathrm{C}$ temos a $S$. paratyphi $\mathrm{C}$, que infecta quase que exclusivamente o homem e difere, antigenicamente, da $S$. cholerae-suis, patógeno primário de porco, apenas por conter ant ígeno Vi (Roantree, 1971). O mesmo é verdade quando se procura uma possível associação entre a presença do didesoxi-hexoses e a virulência de espécies pertencentes a estes grupos sorológi$\cos$. Nos grupos $\mathrm{B}$ e $\mathrm{D}$ estão as espécies de salmonelas mais freqüentemente associadas às infecçōes sistêmicas (Roantree, 1971). As unidades repetidas destes dois grupos diferem principalmente nos didesoxi-açucares ligados à manose, ou seja, no grupo $\mathrm{B}$, a abequose $\mathrm{e}$, no grupo $\mathrm{D}$, a tivelose.

Este fato fez com que um grande número de investigadores procurasse uma possível associação qualitativa dos antígenos 0 destes grupos com a virulência destas salmonelas. Como pode ser visto na Tabela I, no grupo B temos a $S$. paratyphi $\mathrm{B}$ e a $S$. typhimurium $(0: 1,4,5,12)$ agentes de infecçōes sistêmicas no homem e no camundongo, respectivamente. No grupo D estão amostras com um comportamento semelhante ou seja $S$. $t y$ - 
phi $(0: 9,12, \mathrm{Vi})$, agente de infecções sistêmicas no homem e $S$. enteritidis $(0: 1,9,12)$, em camundongos.

\section{TABELA I}

Alguns exemplos de salmonelas freqüentemente associados com infecções sistêmicas no homem e outros mamíferos. Dados modificados de Roantree (1967)

\begin{tabular}{l|c|c}
\hline \multicolumn{1}{c|}{ Espécies } & $\begin{array}{c}\text { Grupos } \\
\text { Sorologicos }\end{array}$ & Fatores do Antigeno O \\
\hline S. paratyphi A & $\mathrm{A}$ & ${ }^{*}(1), \underline{2}^{* *}, 12$ \\
\hline S. paratyphi B & $\mathrm{B}$ & $(1), \underline{4},(5), 12$ \\
S. typhimurium & $\mathrm{B}$ & $(1), \underline{4},(5), 12$ \\
\hline S. paratyphi C & $\mathrm{Cl}$ & $\underline{6} 7 \mathrm{6}$ \\
S. cholerae-suis & $\mathrm{Cl}$ & $\underline{6}$ \\
\hline S. typhi & $\mathrm{D}$ & $\underline{9} 12 \mathrm{Vi}$ \\
S. enteritidis & $\mathrm{D}$ & $(1) \underline{9} 12$ \\
\hline
\end{tabular}

* O parêntese indica que o determinante antigênico pode ser difícil de detectar.

"* Os algarismos sublinhados correspondem aos antígenos "major" de cada grupo.

O conhecimento dos mecanismos genéticos que regulam a síntese deste LPS, permitiram que alguns investigadores avaliassem a influência das modificações qualitativas no antígeno 0 destes grupos sorológicos, na virulência desses germes.

Os resultados de alguns investigadores (Valtonen et al, 1975, Valtonen, 1970), obtidos por tratamento genético, indicaram que mutantes derivadas de uma amostra de $S$. typhimurium de baixa virulência foram mais patogênicas para camundongos inoculados via intraperitoneal, quando sua especificidade sorológica correspondia a $0: 4,5,12$, do que quando a especificidade era $0: 9,12$. O trabalho destes investigadores foi confirmado por Lyman, Stocker \& Roantree (1977), os quais utilizaram ao invés de determinação da LD 50 (empregada pelos primeiros investigadores) a contagem bacteriana no fígado e baço de camundongos inoculados por via intraperitoneal e oral.

Contrariamente a estes resultados, Johnson et al (1974), concluíram que um híbrido de $S$. typhi e $S$. typhimurium com especificidade correspondente a $0: 9,12$, tinha virulência igual para camundongos (LD 50, inoculação intraperitoneal) à da amostra altamente virulenta de $S$. typhimurium.

Lyman, Stocker \& Roantree (1977) chamam a atençāo sobre que suas experiências tanto como as de Valtonen (1970), apenas mostraram variações pequenas na virulência, uma vez que ambas $-S$. typhimurium $(0: 4,5,12)$ e $S$. enteritidis $(0: 9,12)$, são altamente virulentas para estes animais. Embora Makela, Valtonen \& Valtonen (1973) tenham definido a diferença na virulência destas mutantes como pequenas, porém significativas, eles não souberam explicar como o animal discriminaria essas estruturas, chegando assim à diferenciação. Os autores nao conseguiram evidência de que mecanismos de defesa, tais como a fagocitose e o sistema imune, contribuíssem para este comportamento (Makela, Valtonen \& Valtonen, 1973; Valtonen et al, 1971). 
Em relação aos polissacarídios de salmonelas, os gens que controlam a síntese, não só do antígeno 0 como do cerne, foram definidos no cromossoma bacteriano (Stocker \& Makela, 1971).

Em resumo podemos ter mutantes, denominadas de $\mathrm{rfb}$, nas quais ocorre bloqueio na síntese das unidades repetidas do LPS, mutantes $\mathrm{rfc}$, com bloqueio na polimerização e, mutantes rfa, bloqueadas na síntese do cerne. As mutantes rfa e rfb são fenotipicamente rugosas e as $\mathrm{rfc}$ apresentam uma das unidades da cadeia lateral e são denominadas de SR, ou seja, intermediárias entre S e R.

Algumas mutantes rfa apresentam fragmentos de antígenos 0 e são chamadas de mutantes rfa vazantes ("leaky").

Na Figura 1 mostra-se uma representação esquemática do LPS de $S$. typhimurium e de algumas de suas mutantes rugosas.

Uma possível associação do antígeno 0 com a virulência de salmonelas vem-se discutindo a partir dos trabalhos de Lingelsheim (1913, apud Valtonen, 1970) e Arkwright (1927) os quais observaram que a mutação $S \rightarrow R$ era acompanhada de perda de virulência. Posteriormente Thj $\phi$ tta \& Waller (1932) demonstraram que mutantes rugosas de Shigella flexneri, tornam-se sensíveis à ação de anticorpos e complemento.

Seguiu-se a negaçāo do papel deste antígeno na virulência por Pike \& Mackenzie (1940) quando, trabalhando com mutantes lisas de S. typhimurium de virulência elevada e baixa, para camundongos, observaram que estas amostras eram indistinguiveis quanto a características culturais, sorológicas, imunogênicas e tóxicas, nāo diferindo significativamente quanto à invasividade e resistência à tagocitose. A única diferença significativa relacionou-se com a capacidade que tinha a amostra virulenta de multiplicar-se no hospedeiro.

As evidências de que a mutação $S \rightarrow R$ acompanhava-se de perda de virulência foram confirmadas por numerosos investigadores (Nelson \& Roantree, 1967, ficando também demonstrado que, quanto menor a quantidade de polissacarídio no componente rugoso, menos virulentas se tornaram as mutantes para camundongos (Germanier, 1970; Lyman, Steward \& Roantree, 1976; Nakano \& Saito, 1969).

Sobre este último aspecto, a redução na virulência foi muito pequena, e o fato de que os mesmos quimiotipos rugosos, derivados de amostras diferentes, apresentaram grandes variações da virulência, levaram à suposição de que outros fatores, além da parede celular, haviam contribuído para a evidência dessa propriedade (Germanier, 1970).

Vários investigadores têm procurado correlacionar a quantidade de endotoxina de várias salmonelas com sua virulência para animais de laboratório. Alguns pesquisadores não encontraram diferença na quantidade deste antígeno quando compararam amostras lisas de $S$. typhimurium virulentas e avirulentas (Mackenzie, Pike \& Swinney, 1940). Contrariamente, Archer \& Rowley (1969) relataram que amostras lisas altamente virulentas de $S$. typhimurium continham os determinantes $0: 4,5,12$ em concentrações duas vezes maiores que as amostras lisas avirulentas.

Os resultados inicialmente citados foram confirmados por Herzberg (1962) que demonstrou ser igual a LD 50 do LPS de amostras lisas virulentas ou avirulentas. Sobre este aspecto, Nakano \& Saito (1969) concluíram que em mutantes SR e R de $S$. typhimurium, a virulência relacionava-se melhor com o número de cadeias laterais do que com a quantidade total deste antígeno, uma vez que amostras SR, virulentas, continham a mesma quantidade de antígeno que uma mutante rfa "leaky", avirulenta.

A aparente discrepância entre a composição do polissacarídio do LPS e a sua endotoxicidade foi atribuída ao fato que, para matar o hospedeiro por intoxicação, o mi- 
Fig. 1 - Representação esquemática do LPS de S. typhimurium e de suas mutantes rugosas (fundamentada em Germanier, 1970; Lyman, Steward \& Roantree, 1976; Makela, Valtonen \& Valtonen, 1973).

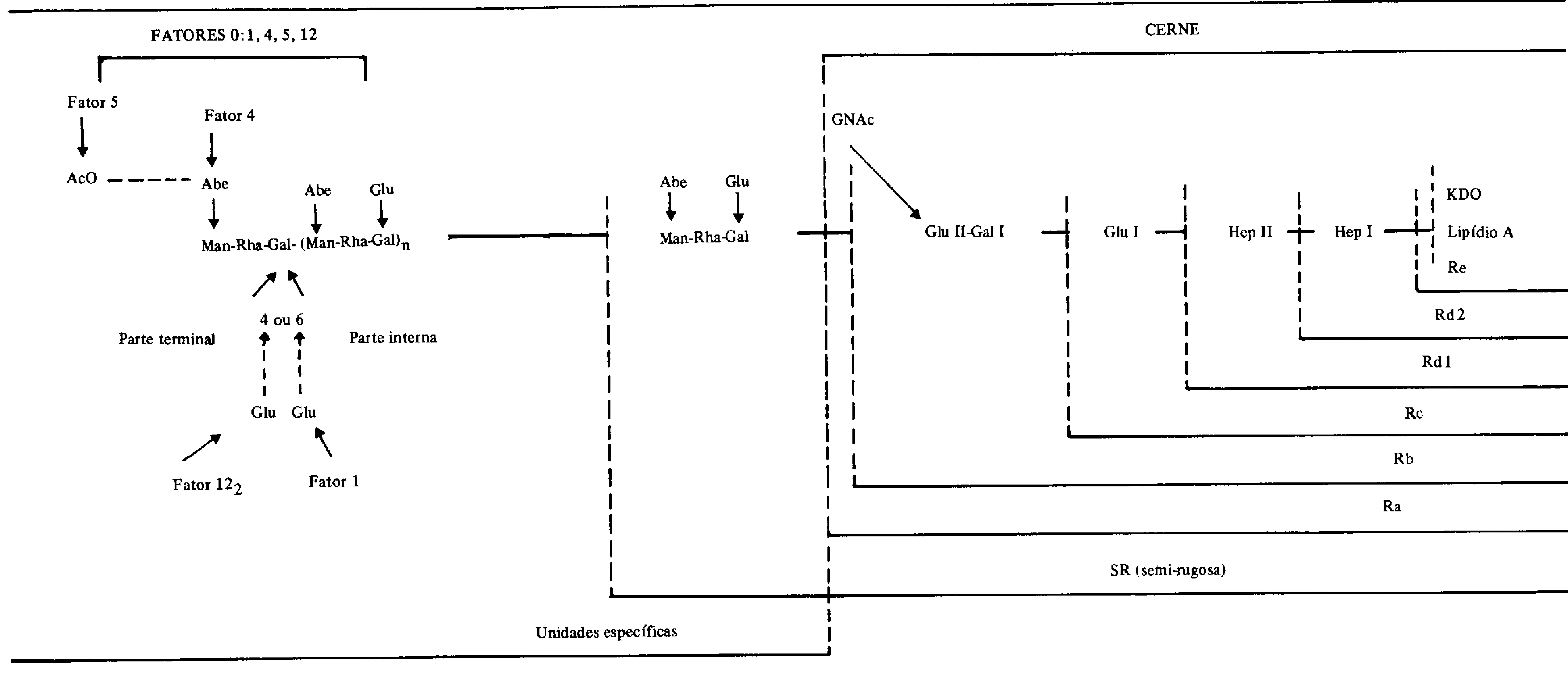

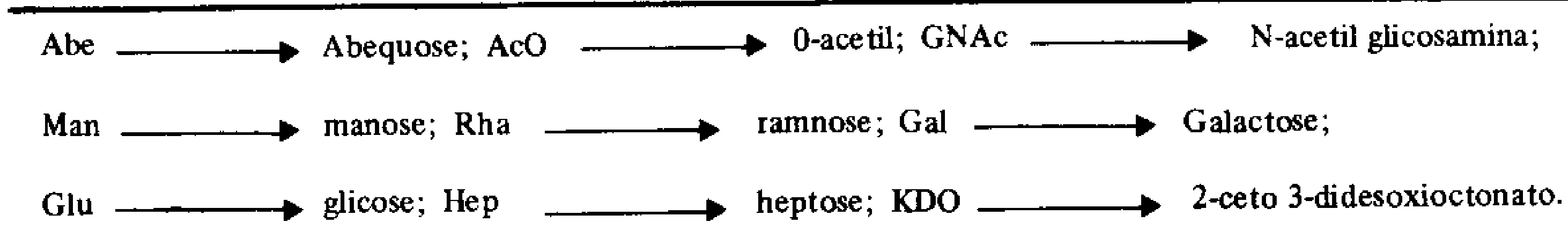


crorganismo deve se multiplicar e produzir quantidade suficiente da endotoxina, o que não pode ocorrer com as amostras avirulentas (Cameron, Holtman \& Jeferies, 1960). A toxicidade de amostras lisas e rugosas com vários tipos de LPS rugosos não se modificou, praticamente, quando usadas amostras mortas (Germanier, 1970). Assim a virulência independeria da atividade endotóxica do LPS que, por sua vez, não estaria relacionada à composição do polissacarídio no LPS.

São conhecidas outras causas de perda de virulência que não a mutação $S \rightarrow R$. Através de métodos genéticos foram obtidas mutantes, em que a perda de virulência estava ligada à incapacidade de síntese de purinas ou aminoácidos. Em relação a purinas a virulência foi readquirida pela reversão à prototrofia, enquanto no caso dos aminoácidos, observou-se que isto pode ou não ocorrer (Herzberg, 1962). No primeiro caso, a avirulência associou-se a uma limitada disponibilidade de fatores de crescimento no hospedeiro, o que impossibilitaria que os germes atingissem a doses tóxicas (Bacon, Burrows \& Yates, 1951). Para Herzberg (1962) a reversão para prototrofia falha, em muitos casos em indicar uma relação direta entre nutrição e virulência.

Em hibridos de amostras avirulentas de $S$. abony e amostras virulentas de $S$. $t y$ phimurium, dois "loci" separados determinaram a avirulência de $S$. abony e, neste caso, a avirulência também não estava relacionada a fatores de crescimento ou ao antígeno 0 (Krishnapillai \& Baron, 1964).

Pelo exposto, os mecanismos precisos subjacentes às mudanças de virulência não foram ainda elucidados e permanece a dúvida sobre se eles estão ligados à própria célula bacteriana ou a fatores de defesa do hospedeiro. Desde que a toxicidade de LPS não é alterada por modificações do polissacarídio, a perda de virulência por mutação $S \rightarrow R$ foi atribuida a um aumento de sensibilidade das mutantes aos fatores de defesa do hospedeiro. Como já referido, as salmonelas que produzem infeç̧ões sistêmicas atingem órgãos e tecidos através do intestino delgado e pouco se sabe sobre os mecanismos bioquímicos ou anatômicos, pelos quais estes microrganismos invadem a mucosa do hospedeiro susceptível. Como antes mencionado, os fatores superficiais que foram definidos como responsáveis pela aderência das células à mucosa não contribuíram para virulência. Em termos de competição com a flora anfibiôntica, sugeriu-se uma participação do ant ígeno 0 como uma possível barreira à açāo tóxica de ácidos graxos (Wardlaw, 1974, apud Smith, 1977).

A possibilidade de uma maior capacidade de penetração de amostras bacterianas lisas no epitélio intestinal, foi negada por Giannella et al (1973), baseados no fato de que a mutaçã $\mathrm{S} \rightarrow \mathrm{R}$ não altera o potencial invasivo de $S$. typhimurium para células cultivadas (HeLa).

A penetração do epitélio intestinal por estes microrganismos, por si só, não seria suficiente para produzir a doença, no que haveria necessidade de sua multiplicação no tecido do hospedeiro susceptível (Formal \& Gemski, 1976; Roantree, 1971). Para Tannock, Blumershine \& Savage (1975) o antígeno 0 talvez seja importante, porém não essencial, ao processo de invasão de $S$. typhimurium através do leo de camundongos. Estes investigadores sugeriram que outras estruturas superficiais e produtos extracelulares, capazes de induzirem à ingestão dessas bactérias pelas células epiteliais, devem ser investigados.

As endotoxinas quando injetadas em animais determinam uma série de efeitos biológicos (Milner, Rudbach \& Ribi, 1971), no entanto, a significação de sua açao tóxica, na patogênese das salmoneloses sistêmicas não está esclarecida (Collins, 1974).

Esta opinião é um dos poucos pontos de que participam os investigadores que discutem patogenia e/ou imunidade destas infecçōes. Entre outros, Neter (1976), relatou: "apesar de numerosas investigações, publicações e muitos congressos nacionais (E.U.A), internacionais e, conferências, o papel preciso das endotoxinas nas infecções humanas por Gram negativos ainda não foi elucidado". 
O que representa esse tipo de antígeno, frente aos mecanismos de defesa do hospedeiro, tem sido discutido por grande número de investigadores e os resultados de alguns destes trabalhos serão a seguir resumidamente relatados.

Um dos mecanismos pelo qual este antígeno participaria na virulência, seria pela maior resistência das formas lisas à ação bactericida do soro e do complemento, como demonstrado pelos resultados já citados de Thjфtta \& Waaler (1932) com amostras lisas e rugosas de Sh. flexneri.

A barreira oferecida pelo antígeno 0 à ação de anticorpos e complemento foi confirmada tanto para salmonelas quanto para outras enterobactérias (Fietta, Romero \& Sicardi, 1977; Luderitz, Staub \& Westphal, 1966; Maaloe, 1948; Reynolds \& Pruul, 1971; Rowley, 1968).

Para explicar tal resistência Rowley (1968) e Chedid et al (1968) sugeriram que a ação estaria ligada a anticorpos contra o "cerne", envolvido pelo antígeno 0 nas amostras lisas. Uma vez que foram descritas amostras quimicamente lisas, virulentas para camundongos e sensíveis à ação do soro (Roantree \& Steward, 1965), tal mecanismo somente seria justificado se nestas amostras houvesse um bloqueio incompleto do "cerne" (Feingold, Goldman \& Kuritz, 1968). A possibilidade de que o polissacarídio do LPS de amostras lisas bloqueiem a interação dos fatores do complemento ativado com os receptores da parede celular foi sugerido por Reynolds \& Pruul (1971).

A atividade bactericida dos soros normais, para amostras lisas e sensiveis, só foi removida por absorção com amostras homólogas (Roantree, 1960).

A principal atuação dos anticorpos específicos de camundongos corresponderia a opsoninas, uma vez que no soro destes animais o sistema de complemento não apresentou atividade bactericida "in vitro" (Marcus, Esplin \& Donaldson, 1954). Em camundongos com um sistema hemolítico completo e, em outros que se mostravam deficientes em um dos seus componentes, foi verificado que os primeiros tinham capacidade de matar $E$. coli, embora não tenha sido possível determinar se o evento realizou-se extracelularmente (Grynn \& Medhurst, 1967).

Em experiências em que amostras lisas, sensíveis à ação de soros, foram colocadas em câmaras "Millipore" na cavidade peritoneal de camundongos, não houve efeito bactericida (Steward \& Roantree, 1961). Ensaios semelhantes em cobaios, demonstraram atividade bactericida específica (Steward, Collis \& Roantree, 1966).

Como acima citado, em camundongos a ação de anticorpos específicos seria opsonizante e, em sua ausência, não haveria fagocitose de amostras de $S$. typhimurium pelos macrófagos, nos estudos "in vitro" (Jenkin \& Banacerraf, 1960), ou na cavidade peritoneal dos camundongos (Blanden, Mackaness \& Collins, 1966).

Este aspecto relacionar-se-ia a uma atividade antifagocitária do antígeno 0 . Tal atividade seria um dos mecanismos pelo qual ele contribuiria para a virulência desses microrganismos, uma vez que mutantes rugosas foram mais sensíveis a fagocitose, quando avaliada "in vivo", por seu rápido desaparecimento do sangue (Biozzi et al, 1963), ou "in vitro", em sistema utilizando macrófagos de camundongos (Fauve, 1964). As observações foram confirmadas utilizando células por aquecimento $\left(60^{\circ} \mathrm{C}, 1\right.$ hora) frente a leucócitos polimorfonucleares, "in vitro" (Stendhal \& Edebo, 1972) o mesmo ocorrendo com o emprego de células HeLa. No último sistema, o efeito somente foi observado quando utilizadas células bacterianas vivas (Kihlstrom \& Edebo, 1976). Biozzi et al (1963) sugeriram que este fenômeno provavelmente estaria ligado a características físico-químicas do antígeno 0 . Posteriormente, o mesmo fato foi atribuído à natureza hidrofilica desse antígeno (Roantree, 1967), bem como à sua carga neutra, em comparação com a carga negativa e o caráter hidrofóbico de mutantes rugosas (Magnusson et al, 1977). Para o mesmo 
grupo de investigadores (Stendahl et al, 1977; Stjernstrom et al, 1977) a função de anticorpos e complemento na fagocitose, seria a de diminuir o caráter hidrofílico da bactéria.

As propriedades físico-químicas do antígeno justificariam, assim, o aumento da atividade fagocitária em relação às formas rugosas. No entanto, a maior sensibilidade de amostras avirulentas à destruição intracelular ainda nāo foi esclarecida. Fauve (1964) verificou que as formas $\mathrm{S}$ de amostras pouco virulentas de $S$. typhimurium foram fagocitadas de maneira semelhante às formas $\mathrm{S}$ de amostras virulentas, mas que, após fagocitose, as primeiras eram destruídas tao rapidamente quanto formas rugosas, enquanto que as amostras virulentas começavam e se multiplicar no interior dos macró fagos. Resultados semelhantes foram observados com outras amostras bacterianas opsonizadas pelo soro normal (Jenkin \& Benacerraf, 1960).

Esses resultados discordaram das experiências anteriores de Furness (1958), nas quais um grande número de bactérias virulentas e avirulentas foram inicialmente mortas por macrófagos normais de camundongos e, então, uma pequena percentagem das virulentas começava a se multiplicar após três horas. Houve confirmação dos resultados por outros investigadores (Blanden, Mackaness \& Collins, 1966; Hsu \& Radcliffe, 1968). Para os últimos, após a destruiçāo inicial, sobreviventes de ambos os tipos ( $1 \%$ de avirulentas e $8 \%$ de virulentas) multiplicaram-se de maneira semelhante.

Em estudos com mutantes rugosas, de cerne completo ou incompleto, de $S$. typhimurium, foi verificado que submetidas à ação da fração lisossomal de leucócitos polimorfonucleares de cobaios, a presença do cerne completo era essencial para a resistência à ação bactericida, enquanto que a cadeia lateral não aumentava esta resistência (Friedberg \& Shilo, 1970). Tagesson \& Stendahl (1973) confirmaram esses resultados, mas relataram que quando utilizaram as frações lisossomais, em sistemas mais aproximados do que ocorre "in vivo", a maior resistência de formas lisas pôde ser observada.

Nos estudos de Friedberg \& Shilo (1970) foi verificado que a opsonização de $S$. typhimurium com soro normal levou a um aumento de resistência destas bactérias à ação bactericida de frações lisossomais de leucócitos polimorfonucleares. Este efeito, no entanto, não se observou em sistema "in vitro" com macrófagos de camundongos (Blanden, Mackaness \& Collins, 1966; Hsu \& Radcliffe, 1968).

Uma avaliação da influência do antígeno 0 frente aos mecanismos humorais específicos no hospedeiro normal torna-se difícil, porque, mesmo com o emprego do mesmo sistema, tal como macrófagos de camundongos "in vitro", numetosas variáveis estão envolvidas em cada um dos trabalhos experimentais referidos. Entre as variáveis, podem citar-se tipos de soro, sua adição ao meio de cultura e/ou ao inóculo, tempo de observação, etc.

Outro condicionante para a virulência de $S$. typhimurium, seria a presença, no germe, de um fator termolábil que apresentaria reação cruzada com tecido do hospedeiro (Rowley \& Jenkin, 1962). Posteriormente sugeriu-se ser este o fator somático 0:5 (Jenkin \& Rowley, 1965). Outros investigadores nāo encontraram evidências de uma participação do mesmo fator na virulência de $S$. typhimurium (Valtonen \& Makela, 1971) nem se encontraram fatores termolábeis em $S$. enteritidis (Collins \& Milne, 1966).

A "febre tifóide murina" é o modelo experimental mais utilizado pelos diferentes investigadores e, nos animais utilizados, mecanismos humorais e celulares estariam envolvidos na proteção (Ushiba, 1965).

$O$ papel de anticorpos para o antígeno 0 na proteção contra a febre tifóide tem sido considerado desde os estudos iniciais. A proteção oferecida por vacinas constituídas de germes inativados por aquecimento foi considerada como evidencia da açāo protetora de anticorpos anti 0 (Arkwright, 1927). 
Vacinas antibacterianas dariam proteçāo para germes que tivessem em comum o antígeno 0 , ou seja, uma vacina de $S$. paratyphi B protegeria contra infecções por $S$. $t y-$ phimurium e uma de $S$. typhi contra $S$. enteritidis (Schutze, 1930). A partir dos trabalhos de Felix \& Pitt (1934b) as atenções de muitos investigadores se voltaram para o papel do antígeno Vi nessas vacinas. Contrariamente aos resultados de Schutze (1930), Landy (1952) relatou que vacinas preparadas a partir de amostras com antígenos 0 diferentes, mas tendo em comum o antígeno $\mathrm{Vi}$, conferiam proteção para $S$. typhi, tal como as vacinas preparadas com amostras homólogas. Esses resultados não foram confirmados por Archer \& Whitby (1957) os quais verificaram que vacinas vivas e inativadas por etanol, de amostras de $S$. cholerae-suis $(0: 6,7)$, davam significante proteção contra infecções, por desafio intraperitoneal, com $S$. paratyphi $\mathrm{C}(0: 6,7, \mathrm{Vi})$, o mesmo näo ocorrendo com vacinas vivas de $S$. typhi $(0: 9,12, \mathrm{Vi})$ embora a última protegesse camundongos contra doses tóxicas.

Nas experiências anteriormente citadas de Steward, Collins \& Roantree (1966), os investigadores haviam verificado que a imunização de cobaios com $S$. typhimurium, não levava ao aparecimento de anticorpos bactericidas para $S$. enteritidis apesar de um fator somático comum $(0: 12)$. Baseados nesses resultados, admitiram que, em $S$. enteritidis, o fator imunogênico mais importante corresponderia a $0: 9$.

$O$ papel de anticorpos para este antígeno foi menos valorizado por experiências que demonstraram a capacidade de mutantes rugosas protegerem camundongos contra infecções por amostras lisas (Nakano \& Saito, 1969; Saito et al, 1962).

O maior poder imunizante das vacinas vivas dividiu a opiniāo dos investigadores, não só quanto ao poder imunizante desta preparação, como sobre os mecanismos imunológicos envolvidos na proteção.

Para o grupo que defende mecanismos mediados por células como a expressão mais significativa da imunidade, o maior poder protetor resulta do fato de que apenas vacinas vivas induzem hipersensibilidade tardia (Collins, 1970; Mackaness, Blanden \& Collins, 1966). De acordo com esses investigadores (Blanden, Mackaness \& Collins, 1966; Mackaness, Blanden \& Collins, 1966) a imunizaçāo ativa com vacinas aquecidas, obtidas a partir de amostras virulentas, ou a transferência passiva do soro de animais imunizados, não produziram grau equivalente de proteção.

$\mathrm{Na}$ opiniāo de outros investigadores, para os quais os anticorpos constituem os fatores de defesa (Jenkin \& Rowley, 1963), o menor poder imunizante de vacinas aquecidas estaria ligado à ausência de constituintes termolábeis e, no caso de $S$. typhimurium, como já referido, do fator somático $0: 5$. Anticorpos para este fator seriam de importân. cia crucial na expressão da imunidade para infecçōes pelo mesmo sorotipo (Jenkin, Karnovsky \& Rowley, 1967).

A ausência de imunidade em camundongos vacinados com $S$. typhimurium contra infecções por $S$. enteritidis, ambas contendo um fator somático comum 0:12, foi interpretada como uma possível independência dos mecanismos imunológicos celulares com relação ao antígeno 0 (Collins \& Mackaness, 1968).

Nos estudos de Germanier $(1970,1972)$ e Germanier \& Furer (1971) a capacidade imunizante de uma série de amostras rugosas de $S$. typhimurium, bem como de amostras virulentas inativadas, foram comparadas em camundongos, considerando as diferentes variáveis, já apontadas, e vias de inoculação, bem como a avaliação baseada na contagem bacteriana no fígado e no baço e a proporçăo de sobreviventes nos grupos vacinado e controle. De acordo com os resultados, a via de imunização não influía significativamente quando considerado o número de bactérias no fígado e baço. No entanto, contrariamente às evidências de outros investigadores, somente mutantes rugosas com capacidade de sintetizar antígeno 0 "in vivo" (mutantes deficientes em uridina difosfato-4-epimerase) fo- 
ram capazes de oferecer um grau de proteção igual ao desenvolvido com doses subletais de amostras virulentas (Germanier \& Furer, 1971).

Germanier (1972) confirmou os resultados anteriormente citados sobre a não participação de fatores termolábeis e do fator 0:12 e sugeriu que mecanismos imunológicos celulares, dependentes da presença do antígeno 0 em células vivas, estariam envolvidas nesta proteção. Estudos posteriores sobre a virulência e poder imunizante da mutante, inoculado por via intraperitoneal em camundongos que receberam tratamento por agentes imunossupressores levaram, entretanto, à conclusão de que a imunidade humoral era de maior importância do que a celular (Morris, Wray \& Sojka, 1976).

\section{Antigenos Comuns do Cerne}

O cerne, ou seja, a parte menos variável da cadeia polissacarídica, é idêntico em todos os sorotipos de salmonelas (Schmidt et al, 1976). Ao contrário do que ocorre com as mutantes $\mathrm{Ra}$ de salmonelas, em $E$. coli cinco tipos diferentes de cernes foram descritos e designados R1, R2, R3, R4 e K-12 (Schmidt, 1973; Schmidt, Jann \& Jann, 1969, 1974). Os tipos R1, R3, e R4 também foram encontrados em certos sorotipos de Shigelas (Mayer \& Schmidt, 1973).

A importância de anticorpos para estas estruturas foi primeiramente enfatizada por Chedid et al (1968), segundo os quais anticorpos anti-Ra de $S$. typhimurium protegiam camundongos contra in fecçбes por microrganismos heterólogos tal a Klebsiella pneumoniae.

Baseado nestas informaçōes, McCabe (1972) desenvolveu uma linha de pesquisa objetivando definir o papel de anticorpos para mutantes inativadas, em infecções experimentais humanas.

Nos estudos iniciais, McCabe (1972) utilizou camundongos como modelo experimental. Nestes animais, uma imunização passiva ou ativa com mutantes $\mathrm{Ra}, \mathrm{Rb}, \mathrm{Rc}, \mathrm{Rd}$, $\mathrm{Rd} 2$ e $\mathrm{Re}$, resultou em proteção significativa somente para ant ígenos comuns, ou seja $\mathrm{Rd} 2$ e $\mathrm{Re}$, quando os animais foram desafiados por $K$. pneumoniae e $E$. coli 107 . Os resultados insatisfatórios com as outras mutantes, excetuando-se o tipo $\mathrm{Rd} l$, foram atribuídos às diferenças existentes entre os diversos tipos de cerne. A imunidade, quando comparada à obtida com amostras homólogas, foi menos efetiva. No entanto, para McCabe (1976) e outros investigadores (Young \& Stevens, 1977) o aumento progressivo na freqüência e letalidade de bacteriemias por estes germes, particularmente em pacientes com a resposta imune comprometida, bem como a impossibilidade de uma imunização específica, dada a diversidade de amostras bacterianas e tipos antigênicos, faz com que a imunização, ativa ou passiva, para antígenos comuns, seja uma tentativa lógica objetivando o controle dessas infecções.

Outros grupos de investigadores, entre eles o de Braude et al (1973) empregando imunização passiva de coelhos para mutantes J5 de $E$. coli correspondente ao quimiotipo $\mathrm{Rc}$ de salmonela (McCabe, 1976), encontraram uma redução significativa na freqüên. cia de reações de Shwartzman locais e sistêmicas, quando estes animais foram desafiados com LPS de amostras lisas heterólogas.

Em infecções humanas indivíduos hospitalizados foram divididos por McCabe (1972), em dois grupos: um com doenças não fatais e outros com doenças fatais. No soro destes indivíduos, em fase inicial da bacteriemia, não houve associaçăo da incidéncia de choque ou morte com um baixo título de anticorpos anti 0 , ao contrário do que ocorreu com anticorpos para o antígeno Re. Quando identificada a natureza dos anticorpos para esses antígenos, Zinner \& McCabe (1976), reafirmaram que, em indivíduós classificados dentro dos mesmos critérios antes referidos, o título de IgG para o antígeno 0 não estava associado com a freqüencia de choque ou morte. Em ambos os grupos, no entanto, inde- 
pendente de anticorpos anti 0 , uma menor freqüência de choque ou morte foi verificada em indivíduos com títulos elevados de anticorpos anti Re. Os investigadores sugeriram que o principal efeito desses anticorpos seria a opsonizaçāo, no.que foram contestados por Young \& Stevens (1977), que não evidenciaram "in vitrọ" tal atividade e sugeriram uma funçāo antitóxica.

\section{Lipidio A}

Um outro compenente comum desses LPS, e para o qual anticorpos foram produzidos quando o LPS foi administrado em condiçōes adequadas, é o lipídio A (Galanos, Luderitz \& Westphal, 1971). Anticorpos antilipídio A foram demonstrados em soros normais humanos e em títulos mais elevados, em pacientes com infecçôes urinárias (Galanos; 1975). Para esse investigador o significado biológico de anticorpos para este antígeno comum ainda não foi definido. Para o grupo de McCabe et al (1977) a imunização passiva ou ativa com lipídio A não protegeu coelhos contra bacteriemias fatais; como ocorreu com mutantes Re.

\section{Antigenos comuns de natureza protéica}

Outros constituintes comuns em parede celular de enterobactérias como lipoproteínas e proteínas começaram a ser estudados recentemente. Quanto d lipoproteínas, demonstraram-se ligadas à cadeia glicopeptídica e, suficientemente expostas na superfície bacteriana, como constituintes comuns a diversas amostras de enterobactérias (Braun, 1975). Em soros de coelhos - obtidos por imunização com células de escherichia, salmonela e shigela - foi demonstrada a presença de anticorpos para estes constituintes. Com mutantes rugosas ( $\mathrm{Ra}$ e $\mathrm{Re}$ ) o título dos anticorpos para esse ant ígeno foi bem mais elevado do que para o LPS, particularmente com mutantes Re (Braun et al, 1976).

O papel desses anticorpos ainda não foi estudado, mas, constituindo um determinante antigênico đisponível na superfície bacteriana, para reações com anticorpos, tal como o antígeno $\operatorname{Re} \mathrm{e}$, tendo se mostrado mais imunogênico que este, teoricamente poderiam ter uma participação nos resultados obtidos com mutantes Re.

No que diz respeito a proteínas, um possivel papel protetor ligado a salmoneloses sistêmicas foi sugerido por Collins \& Mackaness (1968), baseados no fato de que estas, em mistura com adjuvante de Freund incompleto, tal como vacinas de germes não inativados, foram capazes de induzir, em camundongos, fenômenos de hipersensibilidade tardia.

A importância de proteínas comuns à família Enterobacteriaceae, na proteção, particularmer te em relaçāo a salmoneloses, tem sido defendida por Barber \& Eylan $(1947 a, 1975 b)$.

Contrariamente à opiniāo de Collins \& Mackaness (1968) que defendem mecanismos celulares na imunidade contra essas infecçoes, esses acreditam que mecanismos humorais foram os responsáveis pela proteção obtida em seus estudos (Barber \& Eylan, 1977). Ainda de acordo com os mesmos investigadores (Barber \& Eylan, 1974b, 1975a), as modificações resultantes de tratamento genético, baseadas em padrões de aglutinação e atribuídas ao antígeno 0 (Valtonen \& Makela, 1971) relacionaram-se a anticorpos para essas proteínas.

Para os mesmos pesquisadores essas prote ínas sāo comuns às enterobactérias, embora uma proteção específica seja evidenciada com base no grau de mortalidade (DL 100) do grupo controle em relação ao vacinado. Ainda, de acordo com os autores, essas prote ínas ๔ão termoestáveis e de elevada toxicidade para animais de laboratório. 
Admitindo a possibilidade de uma significação clínica desses antígenos comuns, como imunógenos, um dos fatores limitantes das vacinas disponíveis no momento, ou seja, à toxicidade, estaria presente.

\section{Constituintes ribossomais}

As tentativas para encontrar uma fração não tóxica e capaz de proteger o homem com a mesma e fetividade de vacinas vivas, têm levado diversos investigadores à proposiçāo de uma série de substâncias como possíveis imunógenos. Inspirados nos trabalhos iniciais de Youmans \& Youmans $(1964,1965)$ sobre fraçōes ribossomais de Mycobacterium tuberculosis e suas atividades imunogênicas, alguns investigadores, desde então, têm utilizado frações de origem semelhante com uma série de microrganismos, entre eles, a $S$. typhimurium, as quais foram denominadas de "vacinas ribossomais" (Eisentein, 1975).

Existem controvérsias entre os investigadores sobre a identidade da(s) substância(s) protetora(s) para camundongos, presente(s) nestas vacinas. Desse modo a atividade imunogênica foi atribuida a uma proteína (Johnson, 1973), a um complexo proteínaRNA (Margolis \& Bigley, 1972; Smith \& Bigley, 1972a, b), a uma glicoproteina, a um complexo lipoprotéico (Houchens \& Wright, 1973) e, a ácido ribonucleico (Venneman, 1972; Venneman \& Berry, 1971a, b; Venneman, Bigley \& Berry, 1970). Todos esses investigadores afirmaram que suas preparaçōes conferiram um elevado grau de proteção, semelhante ao obtido com vacinas atenuadas e, capazes de estimularem mecanismo de imunidade celular. Posteriormente, alguns pesquisadores atribuíram esta, ou parte desta atividade, à contaminação das fraçōes por endotoxina (Eisentein, 1975; Hoops et al, 1976), enquanto outros atribuíram o poder protetor de vacinas tipo "Venneman" a uma resposta inespecífica, ligada particularmente à linhagem de camundongos utilizados (Medina, Vas \& Robson, 1975). Em um estudo comparativo, Angerman \& Eisentein (1978) concluíram que, apesar de menos tóxicas que vacinas inativadas por acetona, as vacinas ribossomais de $S$. typhimurium nāo apresentaram uma atividade superior quando as primeiras foram administradas em doses adequadas. Ambas apresentaram-se quase tão efetivas quanto às vacinas vivas e, apesar da baixa eficácia de LPS, a probabilidade anteriormente citada sobre a participação deste nos resultados observados, não pôde ser afastada.

\section{Antigeno comum de enterobactérias ( $E C A$ )}

A possibilidade de profilaxia e/ou diagnóstico com um antígeno comum aos microrganismos patogênicos tem sido nos últimos anos o objetivo de muitos investigadores.

Entre estes antígenos, um componente comum apenas à família Enterobacteriaceae foi descrito pela primeira vez por Kunin, Beard \& Halmaguy (1962).

Apesar de não conclusivas, as evidências existentes sobre sua localização na célula bacteriana, sugerem ser este um compenente de superfície, e como tal, poder contribuir para a virulência do germe. Sobre esse aspecto, os trabalhos experimentais são escassos. De acordo com Valtonen et al (1976), mutantes lisas de $S$. typhimurium, ECA positivas, foram estatisticamente mais virulentas, quando inoculadas em camundongos por via intraperitoneal, que as mutantes lisas ECA negativas. Em alguma contradição com esses resultados, investigadores mexicanos (Carrilo, Hashimoto \& Kumate 1966; Kumate et al, 1971 ) concluíram que uma das caracter ísticas de amostras de $E$. coll isoladas durante surtos de diarréia infantil, seria o baixo teor de ECA, quando comparadas com amostras isoladas antes e após o surto.

Em seu trabalho, Valtonen et al (1976) enfatizaram que os mecanismos pelos quais as mutantes de $S$. typhimurium ECA positivas foram mais virulentas que as ECA negativas, næo puderam ser esclarecidos com os testes utilizados, ou seja, ambas apresen taram um comportamento similar em relação à velocidade de multiplicação "in vitro" e ao indice de fagocitose "in vivo". 
Um outro grupo de investigadores (Gorzynski, 1976a; Gorzynski \& Krasny, $1975 \mathrm{a}, \mathrm{c})$ verificou que extratos de tecidos de camundongos, particularmente de fígado, baço e rins, apresentaram antígeno de reatividade cruzada com ECA livre. A presença ou ausência dessa reatividade em determinado órgão variou com a linhagem de animal estudada. Para os autores, isto explicaria a variação e a fraca resposta humoral destes animais, para o antígeno ECA (Gorzynski, Neter \& Ambrus, 1970), bem como uma susceptibilidade a infecções por enterobactérias.

Nos estudos com extrato de tecidos, uma fração solúvel em etanol foi mais efetiva em reaçōes de inibição de hemaglutinação passiva, que extratos aquecidos não purificados. Estas preparaçōes, no entanto, não mostraram capacidade de se ligar a hemácias ou de produzir anticorpos humorais. Quando inoculadas endovenosamente em coelhos, tiveram um comportamento semelhante ao da mistura ECA-LPS de amostras não imunogênicas, ou seja, preparavam o animal para uma resposta secundária por ECA. Dos órgãos utilizados, os extratos de cólon, embora com capacidade de preparar o animal para uma resposta secundária, não se mostraram ativos em reações de hemaglutinação passiva.

Em extratos de tecidos humanos uma atividade semelhante à descrita para camundongos foi demonstrada em órgãos como fígado e rins (Morgenstern \& Gorzynski, 1977). No que diz respeito a extratos de cólon, os resultados deste grupo divergiram dos obtidos por Perlmann et al $(1965,1967)$ e por Lagercrantz et al $(1968)$ os quais demonstraram a presença em ratos e seres humanos de antígeno de reatividade cruzada $\operatorname{com} E$. coli 014 . Esta reatividade cruzada foi demonstrada por testes de hemaglutinação passiva e inibição de hemaglutinação passiva. Uma reatividade ligada a linfócitos $T$ destes pacientes foi demonstrada com a fração solúvel em etanol de $S$. typhimurium em testes de inibição de migração de macrófagos (Bull \& Ignaczak, 1973). Uma vez que tanto o ECA livre (solúvel em etanol) como ECA de E. coli 014 (não solúvel em etanol) não apresentaram diferenças quanto ao determinante antigenico (Neter et al, 1964; Suzuki, Whang \& Neter, 1966) as divergências entre estes pesquisadores provavelmente estão ligadas a diferenças tais como tipo de amostra bacteriana e métodos de purificação.

Os antígenos de cólon foram específicos e se assemelharam ao ECA quanto à sua obtenção pelos mesmos métodos, resistência ao aquecimento, capacidade de sensibilizar hemácias, etc. Posteriormente Carlsson et al (1978) definiram como glicoproteína, um componente isolado de fezes e cólon de ratos. Esta glicoprote ína foi sensível à oxidação por periodato, à hidrólise ácida fraca, e reagiu com $40 \%$ dos soros de pacientes com colite ulcerativa. As relações antigênicas entre esta glicoproteína e extratos de E. coll 014 não foram determinadas.

Além da participação deste ECA de E. coli 014 na patologia de colites ulcerativas, uma possível associação com pielonefrites crônicas tem sido defendida pelo grupo de Holmgren et al (1972). Desta maneira, a participação de ECA na patogenia de afecções e infecçōes humanas não está definida. Ainda menos definida, sob o ponto de vista biológico, é sua importância no diagnóstico ou como imunógeno.

Na avaliação de uma possivel proteção por ECA, dois modelos experimentais têm sido utilizados. Um dos modelos é o tradicionalmente utilizado em salmoneloses sistêmicas, ou seja, "a febre tifóide murina", enquanto o outro correspondeu a pielonefrites experimentais em coelhos.

Em camundongos, uma imunização ativa, com ECA, ou passiva, com soro imune de coelho, e, um desafio endovenoso por $S$. typhimurium, resultou em pequeno grau de proteçāo, quando avaliada a percentagem de sobreviventes entre os grupos vacinados e controle (Gorzynski, Ambrus \& Neter, 1971; Gorzynski \& Krasny, 1975b). Estes resultados foram atribuídos, como anteriormente mencionado, a uma falta de resposta ao estímulo antigênico, devida aos ant ígenos de reatividade cruzada com ECA nos tecidos desses animais. 
Para o grupo de McCabe (McCabe, 1976; McCabe \& Creely, 1973; McCabe et al, 1973), camundongos de linhagem CFI, diferentes das utilizadas pelos investigadores acima referidos, apresentaram uma boa resposta humoral para ECA. Nestes animais a proteção obtida por imunização ativa ou passiva com E. coli 014 , estava relacionada a anticorpos para a porção do cerne (Re) e não para ECA. Estes restiltados não foram aceitos por Makela \& Meyer (1976) que os atribuíram à presença, nas preparações daquele grupo, de um outro antígeno comum, que não o de Kunin.

No relativo ao outro modelo animal, ou seja, pielonefrite experimental em coethos, os resultados parecem mais esclarecedores. Nesses animais a imunização com a fração solúvel em etanol, ou a imunização passiva, resultaram em boa proteçao, para desafios com enterobactérias (Domingue et al, 1970).

O mecanismo pelo qual anticorpos anti ECA protegeram estes animais, atribuiuse à sua capacidade opsonizante, avaliada por testes "in vitro" com leucócitos polimorfonucleares de coelhos (Domingue \& Neter, 1966a,b), uma vez que essas células não apresentaram atividade bactericida para outras amostras que nâo a $E$. coli 014 (Domingue \& Neter, 1966a; Kunin \& Beard, 1963).

Essa interpretação, no entanto, não encontrou apoio nas investigações de Whang, Yagi \& Neter (1967) e McCabe \& Greely (1973) para os quais a resposta desses animais (coelhos) para ECA constitui-se apenas de anticorpos tipo IgM, cuja ação protetora seria pouco provável no modelo experimental utilizado.

No homem, os dados experimentais relativos a um provável papel de anticorpos na proteção, restringiram-se às evidèncias de McCabe, Kreger \& Johns (1972) e McCabe, Johns \& DiGenio (1973) os quais negaram a significação de anticorpos circulantes para ECA em pacientes com bacteriemias.

As evidências de um possível papel protetor de anticorpos para ECA em animais de laboratório, sua inocuidade para estes animais (Kessel, Neter \& Braun, 1966) e para o homem (Gorzynski et al, 1972) levaram alguns (McLaughlin \& Domingue, 1974) à sugestão de que este imunógeno seria de grande importância, como vacina, na profilaxia de infecções por enterobactérias.

O fato de que este ant ígeno, quando inoculado em cobaios com o adjuvante de Freund completo, induziu fenômenos de hipersensibilidade tardia (Morgenstern \& Gorzynski, 1973) seria mais um fator em favor de seu emprego como vacina. No entanto, como já mencionado, a suposição de uma provável participação do ECA na patogenia de certas doenças auto-imunes, fez com que fosse recomendada cautela quanto d̀ sua aplicação clínica, até que elucidado seu papel real nas infecções por enterobactérias (Ģorzynski, 1976b).

Com relação a uma possível aplicação clínica do título de anticorpos para ECA no diagnóstico, alguns resultados têm sido promissores e outros pouco satisfatórios, dependendo do tipo de infecção.

Em soros normais, a avaliação do título de anticorpos anti ECA data dos trabalhos de Kunin $(1962,1963)$ e Kunin \& Beard (1963). De acordo com esses resultados o título dos anticorpos é extremamente baixo em soros fetais quando comparados aos soros maternos. A partir de seis meses os títulos de anti ECA se correlacionaram aos obtidos para 0 antígeno 0 .

Resultados similares foram publicados por Whang \& Neter (1963), segundo os quais, o título máximo de anti ECA no soro de indivíduos normais e em preparações comerciais de gama globulina foi de um para quarenta. 
Em infecções, o aumento do título de anti ECA seguiu um padrão relacionado ao tipo de infecção. Em casos de enterites, por salmonelas ou $E$. coli, infecções urinárias agudas ou, bacteriemias, anticorpos anti ECA foram demonstrados ocasionalmente, em baixos títulos (Andersen, 1966; Carter et al, 1968; Diaz \& Neter, 1968; McCabe, Johns \& DiGenio, 1973; McCabe, Kreger \& Johns, 1972; Vosti et al, 1964).

Em outras condições, como em shigelose, peritonites (Griffiths, Yoonessi \& Neter, 1977) e infecções urinárias crônicas (Andersen, 1966; Saito, 1967; Whang \& Neter, 1963) um aumento significativo no título de anti ECA foi observado.

Quando os títulos de anticorpos anti ECA foram comparados ao obtido para um outro antígeno comum, ou seja, a lipoproteína, o padrão de respostas para ambos diferiu com o tipo de infecçāo (Griffiths, Yoonessi \& Neter, 1977). Para esses investigadores, em pacientes com bacteriemias e doenças malígnas um título elevado de anticorpos foi evidenciado somente em relação à lipoproteína, o que justificaria os resultados insatisfatórios de McCabe, Kreger \& Johns (1972) e McCabe, Johns \& DiGenio (1973) quanto a anticorpos para ECA.

No que diz respeito a pacientes com febre tifóide, foi observado que em dois, de oito casos, houve um aumento significativo no título de anti ECA (Diaz \& Neter, 1968).

Destas infecções, o significado do título desses anticorpos como ajuda no diagnóstico clínico tem sido discutido particularmente em relação às infecções renais, como a pielonefrite. Para alguns pesquisadores, o título de anti ECA serviria como indicador destas infecções (Saito, 1967; Thomsen \& Hjort, 1977; Whang \& Neter, 1963), enquanto outros negaram tal correlação (Andersen, 1966; Carter et al, 1968; Sanford et al, 1978).

Ainda no que diz respeito a este tipo de infecções, Aoki, Merkel \& McCabe (1966) e Aoki et al (1967) sugeriram que testes de imunofluorescência, com imunessoro anti ECA, poderia ser uma maneira fácil e útil de demonstrar ant ígenos bacterianos no tecido renal, uma vez que substituiria uma grande quantidade de soros específicos para diferentes amostras de $E$. coli e outras enterobactérias. Em pielonefrites crônicas a presença destes antígenos foi demostrada em seis de sete casos de pielonefrites abacterianas (Aoki et al, 1969).

Tais resultados, no entanto, não foram confirmados por Schwarz \& Cotran (1973) e por Thomsen \& Hjort (1973) segundo os quais, somente em pielonefrites agudas foi possível a evidenciação deste antígeno no tecido renal.

As possíveis implicações do antígeno ECA na virulência, patogênese, imunidade e diagnóstico não foram ainda, como se segue da presente revisão, perfeitamente elucidadas.

Há evidências de que em seres humanos, tal como ocorreu em coelhos, a imunização com a fração ECA semipurificada (fração solúvel em etanol) produza um aumento significativo de anticorpos anti ECA (Gorzynski et al, 1972).

De nossas observaçðes (Milhomen, 1979) a imunização de indivíduos com vacinas contendo antígeno ECA, no caso, a vacina antitifoídica, não provocou resposta humoral para este antígeno. Esse fato não exclui uma possível participação do antígeno na imunidade antitifoídica uma vez que, tal como ocorre em coelhos, esta vacina pode preparar o homem para uma rápida resposta secundária ao agente bacteriano. Resta salientar que mutantes rugosas, quando viáveis, foram imunogênicas para ECA independente da amostra bacteriana original.

Foi mencionado que estas mutantes oferecem uma maior imunidade que vacinas inativadas. Não tendo sido definido os determinantes antigênicos responsáveis por esta proteção, a participação do ECA deveria ser investigada. 


\section{SUMMARY}

The results of the work done from the beginning of the century up to the present were reviewed, leading to the conclusion that the large amount of available knowledge on the chemistry, immunological, antigenic, and biological aspects of the antigens of Salmonella, was not sufficient to determine which antigen(s) accounted for immune protection on systemic salmonellosis.

Data accumulated on numerous and diversified preparations being used as immunogens, as well as on several experimental models and different methods of studying the immune response. In relation to Salmonella typhi, given that this microorganism is an exclusive natural pathogen only for man, the results of protection obtained with laboratory animal experiments, often, did not show any correlation with observed facts in the human being.

It should be mentioned, however, that the search for an immune response has been restricted, in most instances to the $0, \mathrm{H}$ and $\mathrm{Vi}$ antibodies, and to active or passive protective tests with mice. Cell mediated immunity has been evaluated mainly by using skin tests with chemically ill defined and variable protein preparations.

No definitive hypothesis is available, at present, related to the mechanism(s) of immune protection operating on systemic salmonellosis.

\section{REFERENCIAS BIBLIOGRĀFICAS}

ANDERSEN, H.J., 1966. Studies of urinary tract infection in infancy and childhood. VII - The relation of $E$. coli antibodies in pyelonephritis as measured by homologous and common (Kunin) antigens. J. Pediatr., $68: 542-550$.

ANDERSON, E.S. \& GUNNELL, A., 1964. A suggestion for a new anti-typhoid vaccine. Lancet, 2 $: 1196-1200$,

ANDRADE, J.RC., 1979. Papel da adesividade mediada por fímbrias na ceratoconjuntivite experimental por Shigella flexneri. Tese de Mestrado. Instituto de Microbiologia, U.F.R.J., Rio de Janeiro, $156 \mathrm{p}$.

ANGERMAN, C.R. \& EISENTEIN, T.K., 1978. Comparative efficacy and toxicity of a ribossomal vaccine, acetone-killed cell, lipopolysaccharide and a live cell vaccine prepared from Salmonella typhimurium. Infect. Immun., 19 :575-582.

AOKI, S.; IMAMURA, S.; AOKI, M. \& MCCABE, W.R., 1969. "Abacterial" and bacterial pyelonephritis. Immunofluorescent localization of bacterial antigen. $N$. Engl. J. Med., $281: 1375-1382$.

AOKI, S.; MERKEL, M.; AOKI, M. \& McCABE, W.R., 1967. Immunofluorescent localization of bacterial antigen in pyelonephritis. $I$ - The use of antisera against the common enterobacterial antigen in experimental renal lesions. J. Lab. Clin. Med. $70: 204-212$.

AOKI, S.; MERKEL, M.; McCABE, W.R., 1966. Immunofluorescent demonstration of the common enterobacterial antigen. Proc. Soc. Exp. Biol. Med., $121: 230 \cdot 234$.

ARCHER, G.T.L. \& WHITBY, J.L., 1957. Protection of mice by living Vi and O vaccines against death caused by Salmonella paratyphi C. J. Hyg., 55 :513-526.

ARCHER, J.R. \& ROWLEY, D., 1969. A quantitative comparison of the antigenic structure of a virulent ard an avirulent strain of Salmonella typhimurium. Immunology. 17:551-558.

ARKWRIGHT, J.A., 1927. The value of different kinds of antigen in prophylactic "enteric" vaccines. J. Pathol. Bacteriol. $30: 345-364$. 
ASHIDA, T., 1949. Studies on the antigenic substances of Eberthella typhosa. Jap. J. Exp. Med., $20: 181-209$.

BACON, G.A.; BURROWS, T.W. \& YATES, V.M., 1951. The effects of biochemical mutation on the vi nulence of Bacterium typhosum: the loss of virulence of certain mutants. Brit. J. Exp. Pathol., $32: 85-96$.

BAKER, E.E.; WHITESIDE, R.E.; BASCH, R. \& DEROW, M.A., 1959. The Vi antigens of Enterobacteriaceae. I - Purification and chemical properties. J. Immunol., $83: 680-683$.

BARBER, C. \& EYLAN, E., 1974a. The proteins from Salmonella enteritidis; their protective role in mice, and the antibodies induced during infection with the homologous strain. Zentralbl. Bakteriol. Parasitenkd. Infectionskr. Hyg. Abt. Orig. Reihe A, 226 :331-335.

BARBER, C. \& EYLAN, E., 1974b. The heat resistant antigens of Salmonella paratyphi A and their relationship to Salmonella typhi and Salmonella typhimurium. Zentralbl. Bakteriol. Parasitenkd. Infektionskr. Hyg. Abt. Orig. Reihe A, 226 :324-330.

BARBER, C. \& EYLAN, E., 1975a. Unrelatedness between agglutinations of bacteria and the presence of antipolysaccharides in sera of Salmonellae groups B and D. Zentralbl. Bakteriol. Parasitenkd. Infektionskr. Hyg. Abt. Orig. Reihe A, 233 :180-187.

BARBER, C. \& EYLAN, E., 1975b. Confirmation of the protective role of proteins from Salmonella typhimurium in infection of mice with their natural pathogen. Zentralbl. Bakteriol. Parasitenkd. Infektionskr. Hyg. Abt. Orig. Reih A, $230: 461465$.

BARBER, C. \& EYLAN, E., 1977. Behaviour of Salmonellae non pathogenic for mice. I - Neutralization of their toxicities by induced antiprotein antibodies. Zentralbl. Bakteriol. Parasitenkd. Infektionskr. Hyg. Abt. Orig. Reihe A, 237 :213-221.

BENENSON, A.S., 1964. Serological responses of man to typhoid vaccines. Bull. W.H.O., $30: 653-662$.

BEUMER, J., 1974. Les vaccins antibactériens: des microbes vivants aux antigènes purifiés. Bull. Inst. Pasteur, $72: 35-48$.

BIOZZI, G.; STIFFEL, C.; Le MINOR, L.; MOUTON, D. \& BOUTHILLIER, Y., 1963. Etude quantitative de l'effect opsonizant des immunsérums sur la phagocytose des Salmonella par les cellules du système réticulo-endothélial in vivo. Ann. Inst. Pasteur, 105 :635-666.

BLANDEN, R.V.; MACKANESS, G.B. \& COLLINS, F.M., 1966. Mechanisms of acquired resistance in mouse typhoid. J. Exp. Med., $124: 585-600$.

BRAUDE, A.L.; DOUGLAS, H. \& DAVIS, C.E., 1973. Treatment and prevention of intravascular coagulation with antiserum to endotoxin. J. Infect. Dis. (Suppl.), $128: 157-164$.

BRAUN, V., 1975. Covalent lipoprotein from the outer membrane of Escherichia coli. Biochem. Biophys. Acta, $415: 335-377$.

BRAUN, V.; BOSCH, V.; KLUMPP, E.R.; NEFF, I.; MAYER, H. \& SCHLECHT, S., 1976. Antigenic determinants of murein-lipoprotein and its exposure at the surface of Enterobacteriaceae. Eur. J. Biochem., 62 :555-556.

BULL, D.M. \& IGNACZAK, T.F., 1973. Enterobacterial common antigen-induced lymphocyte reactivity in inflamatory bowel disease. Gastroenterology, 64 :43-50.

CAMERON, J.A.; HOLTMAN, D.F. \& JEFERIES, C.D., 1960. The association of virulence with endotoxins in Salmonella pullorum. J. Infect. Dis., $106: 159-161$.

CARLINFANTI, E., 1946. Progrès récents dans l'étude des antigènes et des anticorps typhoidiques. An. Inst. Pasteur, 72 :766-782.

CARLSSON, H.E.; SUNDBLAD, G., HAMMARSTROM, S.; PERLMANN, P. \& GUSTAFSON, B.E., 1978. Immunological studies in ulcerative colitis. Extraction, fractionation, and immunological characterization of germ-free rat colon antigen. Arch. Biochem. Biophys., $187: 366-375$. 
CARRILlO, J.; HASHIMOTO, B. \& KUMATE, J., 1966. Content of heterogenetic antigen in Escherichia coli and its relationship to diarrhea in newborn infants. J. Infect. Dis., $106: 285-296$.

CARTER, M.J.; EHRENKRANZ, N.J.; BURNS, J. \& CASSADY, J.C., 1968. Serologic response to heterologous Escherichia serogroups in women with pyelonephritis. N. Engl. J. Med., 279 :1407-1412.

CARTER, P.B. \& COLLINS, F.M., 1977. Assessment of typhoid vaccines by using the intraperitoneal route of challenge. Infect. Immun., $17: 555-560$.

CHEDID, L.; PARANT, M.; PARANT, F. \& BOYER, F., 1968. A proposed mechanism for natural immunity to enterobacterial pathogens. J. Immunol., $100: 292-301$.

COLLINS, F.M., 1970. Immunity to enteric infection in mice. Infect. Immun., 1 :243-250.

COLLINS, F.M., 1974. Vaccines and cell-medianted immunity. Bacteriol. Rev., $38: 371-402$.

COLLINS, F.M. \& MACKANESS, G.B., 1968. Delayed hypersensitivity and Arthus reactivity in relation to host resistance in Salmonella-infected mice. J. Immunol., $101: 830-845$.

COLLINS, F.M. \& MILNE, M., 1966. Heat-labile antigens of Salmonella enteritidis. II - Mouse-protection studies. J. Bacteriol., $92: 549-557$.

DIAZ, F. \& NETER, E., 1968. Antibody response to the common enterobacterial antigen of children with shigellosis, salmonellosis, or urinary tract infection. Amer. J. Med. Sci., 256 :18-24.

DIENA, B.B.; JOHNSON, E.M.; BARON, L.S.; WALLACE, R. \& GREENBERG, L., 1973. Assay of typhoid vaccines with Salmonella typhosa-Salmonella typhimurium hybrids. Infect. Immun., $7: 5-8$.

DIENA, B.B.; RYAN, A.; WALLACE, R.; ASHTON, F.R.; JOHNSON, E.M. \& BARON, L.S., 1975. Ineffectiveness of $\mathrm{Vi}$ and chemically treated endotoxins on typhoid vaccines in mice challeged with a Salmonella typhosa-Salmonella typhimurium hybrid. Infect. Immun., $12: 1470-1471$.

DIENA, B.B.; RYAN, A.; WALLACE, R.; JOHNSON, E.M.; BARON, L.S.; \& ASHTON, F.E., 1977. Effectiveness of parenteral and oral typhoid vaccination in mice challeged with a Salmonella typhi-Salmonella typhimurium hybrid. Infect. Immun., $15: 997-998$.

DOMINGUE, G.J. \& NETER, E., 1966a. Opsonizing and bactericidal activity of antibodies against common antigen of Enterobacteriaceae. J. Bacteriol., $91: 129-133$.

DOMINGUE, G.J. \& NETER, E., 1966b. Inibition by lipopolysaccharide of immune phagocytosis of latex particles modified with common antigen of enteric bacteria. Proc. Soc. Exp. Biol. Med., $121: 133-137$.

DOMINGUE, G.J.; SALHI, A.; ROUNTREE, C. \& LITTLE, W., 1970. Prevention of experimental hematogenous and retrograde pyelonephritis by antibodies against enterobacterial common antigen. Infect. Immun., 2 :175-182.

DUGUID, J.P.; ANDERSON, E.S. \& CAMPBELL, I., 1966. Fimbriae and adhesive properties in Salmonellae. J. Pathol. Bacteriol. 92 :107-138.

DUGUID, J.P.; DAREKAR, M. R \& WHEATER, D.W.F., 1976. Fimbriae and infectivity in Salmonella typhimurium. J. Med. Microbiol., $9: 459-473$.

EDSALL, G.; CARLSON, M.C.; FORMAL, S.B. \& BENENSON, A.S., 1959. Laboratory tests of typhoid vaccines used in a controlled field study. Bull. W.H.O., $20: 1017-1032$.

EDWARDS, E.A.; JOHNSON, D.P.; PIERCE, W.E. \& PECKINPAUGH, RO., 1974. Reaction and serologic responses to monovalent acetone-inactivated typhoid vaccine and heat-killed $\mathrm{TAB}$ when given by jet infection. Bull. W.H.O., $51: 501-505$.

EDWARDS, P.R. \& EWING, W.H., 1972. Identification of Enterobacteriaceae. 3a ed., Burgess Publishing Co., Minneapolis, Minnesota. 
EIGUER, T.; BINSTEIN, N.; CETRANGOLO, R. \& STAUB, A.M., 1970. Recherche du pouvoir protecteur pour l'embryon de poulet de divers sérums anti-Salmonella typhi de lapin et d'homme. Ann. Inst. Pasteur. $119: 646-662$.

EISENTEIN, T.K., 1975. Evidence for O antigens as the antigenic determinants in "ribusomal" vaccines prepared from Salmonella. Infect. Immun., $12: 364-377$.

FAUVE, M.R., 1964. Résistance cellulaire a l'infection bactérienne. II - Comportement de macrophages de souris entretenus, "in vitro", dans un milieu sans sérum en présence de Salmonella typhimurium d'inégale virulence. Ann. Inst. Pasteur. $107: 472-483$.

FEINGOLD, D.S.; GOLDMAN, J.M. \& KURITZ, H.M., 1968. Locus of the lethal event in the serum bactericidal reaction. J. Bacteriol., $96: 2127-2131$.

FELIX, A., 1951. The preparation, testing and standardization of typhoid vaccine. J. Hyg., 49 $: 268-287$.

FELIX, A., 1952. The properties of different Salmonella Vi antigens. J. Hyg., $50: 515-539$.

FELIX, A. \& PITT, R.M., 1934 a. Virulence of B. typhosus and resistance to O antibody. J. Pathol. Bacteriol., 38 :409-420.

FELIX, A. \& PITT, R.M., 1934b. A new antigen of $B$. typhosus. Its relation to virulence and to active and passive immunization. Lancet, $227: 186-191$.

FELIX, A. \& PITT, R.M., 1951. The pathogenic and immunogenic activities of Salmonella typhi in relation to its antigenic constituents. J. Hyg., $49: 92-110$.

FIETTA, A.; ROMERO, E. \& SICCARDI, A.G., 1977. Effect of some R factor on the sensitivity of rough Enterobacteriaceae to human serum. Infect. Immun., $18: 278-282$.

FORMAL, S.B. \& GEMSKI, P., 1976. Studies on the pathogenesis of intestinal disease caused by invasive bacteria. Zantralbl. Bakteriol. Parasitenkd. Infektionskr. Hyg. Abt. Orig. Reihe A, $235: 9-12$.

FRIEDBERG, D. \& SHILO, H., 1970. Interaction of Gram-negative bacteria with the lysosomal fraction of polumorphonuclear leukocytes. Infect. Immun., 1 :305-310.

FURNESS, G., 1958. Interaction between Salmonella typhimurium and phagocytic cells in cell culture. J. Infect. Dis., $103: 272-277$.

GAINES, S.; CURRIE, J.A. \& TULLY, J.C., 1960. Production of incomplete Vi antibody in mice. Proc. Soc. Exp. Biol. Med., $104: 602-605$.

GAINES, S.; CURRIE, J.A. \& TULLY, J.C., 1965. Factors affecting formation of incomplete Vi antibody in mice. J. Bacteriol. $90: 635-642$.

GALANOS, C., 1975. Physical state and biological activity of lipopolysaccharides. Toxicity and immunogenicity of the lipid A component. Z. Immunitaestsforsch., $149: 214-229$.

GALANOS, C.; LUDERITZ, O. \& WESTPHAL, O., 1971. Preparation and properties of antisera against the lipid-A component of bacterial lipopolysaccharides. Eur. J. Biochem. 24 :116-122.

GERMANIER, R., 1970. Immunity in experimental salmonellosis. I - Protection induced by rough mutants of Salmonella typhimurium. Infect. Immun., 2 :309-315.

GERMANIER, R., 1972. Immunity in experimental salmonellosis. III - Coriuparative immunization with viable and heat-inactivated cells of Samonella typhimurium. Infect. Immun., 5 :792-797.

GERMANIER, R. \& FURER, E., 1971. Immunity in experimental salmonellosis. II - Basis for the avirulence and protective capacity of gal E mutants of Salmonella typhimurium. Infect. Immun., 4 :663-673. 
GIANELLA, R.A.; WASHINGTON, O.; GEMSKI, P. \& FORMAL, S., 1973. Invasion of Hela cells by Salmonella typhimurium: a model for study of invasiveness of Salmonella. J. Infect. Dis., 128 :69-75.

GLYNN, A.A. \& MEDHURST, F.S., 1967. Possible extracellular and intracellular bactericidal actions of mouse complement. Nature, $213: 608-610$.

GORZYNSKI, E.A., 1976a. Cross-reactivity between mouse tissue and enterobacterial common antigen (CA). Mil. Med., $141: 610-612$.

GORZYNSKI, E.A., 1976b. Biologic significance of enterobacterial common antigen (CA) and engendered antibodies. Mil. Med., 141 :696-699.

GORZYNSKI, E.A.; AMBRUS, J.L. \& NETER, E., 1971. Effeet of common enterobacterial antiserum in experimental Salmonella typhimurium infection of mice. Proc. Exp. Biol. Med., 137 :1209-1212.

GORZYNSKI, E.A. \& KRASNY, S.A., 1975a. Immunological mimicry between mouse tissues and enterobacterial common antigen. Immunol. Commun., 4 :39-49.

GORZYNSKI, E.A. \& KRASNY, S.A., 1975b. Effect of erythrocytes treated with enterobacterial common antigen of experimental Salmonella typhimurium infection of mice. Med. Microbiol. Immunol., $161: 163-170$.

GORZYNSKI, E.A. \& KRASNY, S.A., 1975c. Cross-reactivity between organ extracts of gnotobiotic mice and enterobacterial common antigen. J. Reticuloendothel. Soc., 17 :346-352.

GORZYNSKI, E.A.; NETER, E. \& AMBRUS, J.L., 1970. Differences in antibody response of mouse strains to enterobacterial common antigen. Proc. Soc. Exp. Biol. Med., 134 :776-779.

GORZYNSKI, E.A.; OSS, C.J. Van; AMBRUS, J.L. \& NETER, E., 1972. The hemagglutinin response of human subjects to common enterobacterial antigen. Infect. Immun., $5: 625-626$.

GRABAR, J. \& Le MINOR, S., 1951. Test de séro-protection antityphoidique sur l'embryon de poulet. Ann. Inst. Pasterur, 81:528-540.

GRIFFITHS, E.K.; YOONESSI, S. \& NETER, E., 1977. Antibody response to enterobacterial lipoprotein of patients with varied infections due to Enterobacteriaceae. Proc. Soc. Exp. Biol. Med., 154 :246-249.

HEJFEC, L.B.; SALMIN, L.V.; LEJTMAN, M.Z.; KUZ'MINOVA, M.L.; VASIL'EVA, A.V.; LEVINA, L.A.; BENCIANOVA, T.C.; PAVLOVA, E.A. \& ANTONOVA, A.A., 1966. A controlled field trial and laboratory study of five typhoid vaccines in the USSR. Bull. W. H. O., 34 :321-339.

HERZBERG, M., 1962. Living organims as immunizing agents against experimental salmonellosis in mice. I - Virulence of auxotrophic mutants. J. Infect. Dis., $111: 192-203$.

HOLMGREN, J.; HAMMARSTROM, S.; HOLM, S.E.; AHLMAN, J.; ATTMAN, P.O. \& JODAL, U., 1972. An antigenic relationship between human kidney, colon and the common antigen of Enterobacteriaceae. Int. Arch. Allergy. Appl. Immunol. 43 :89-97.

HOOPS, P.; PRATHER, N.E.; BERRY, L.J. \& RAVEL, J.M., 1976. Evidence for an extrinsic immunogen in effective ribosomal vaccines from Salmonella typhimurium. Infect. Immun., 13 $: 11841192$.

HORNICK, R.B.; GREISMAN, S.E.; WOODWARD, T.E.; DUPONT, H.L.; DAWKINS, A.T. \& SNYDER, M.J., 1970. Typhoid fever: pathogenesis and immunologic control (first of two parts). N. Engl. J. Med., $283: 686-691$.

HOUCHENS, D.P. \& WRIGHT JR., G.L., 1973. Immunity to Salmonella typhimurium infection: caracterization of antigens in active protection by polyacrylamide gel electrophoresis. Infec. Immun., 7 :507-511.

HSU, H.S. \& RADCLIFF, A.S., 1968. Interactions between macrophages of guinea pigs and Salmonellae. I Fate of Salmonella typhimurium within macrophages of normal guinea pigs. J. Bacteriol., $96: 191-197$. 
JARVIS, F.G.; MESENKO, M.T. \& KYLE, J.E., 1960. Eletrophoretic purification of the Vi antigen. J. Bacteriol., $80: 677-682$.

JARVIS, F.G.; MESENKO, M.T.; MARTIO, D.G. \& FERRINE, T.D., 1967. Physicochemical properties of the $\mathrm{Vi}$ antigen before and after mild alkaline hydrolisis. J. Bacteriol., $94: 1406-1410$.

JENKIN, C.R. \& BENACERRAF, B., 1960. In vitro studies on the interaction between mouse peritoneal macrophages and strains of Salmonella and Escherichia coli. J. Exp. med. $112: 403-417$.

JENKIN, C.R.; KARNOVSKY, M.L. \& ROWLEY, D., 1967. Praparation of an artificial antigen and immunity to mouse typhoid. Immunology, $13: 361-372$.

JENKIN, C.R. \& ROWLEY, D., 1963. Basis for immunity to typhoid in mice and the question of "cellular immunity". Bacteriol. Rev., 27 :391-404.

JENKIN, C.R. \& ROWLEY, D., 1965. Partial purification of the protective antigen of Salmonella typhimurium and its distribution among various strains of bacteria.Aust. J. Exp. Biol. Med. Sci., $43: 65-78$.

JOHNSON, E.M.; SNELLINGS, N.J.; LIFE, C.A. \& BARON, L.S., 1974. Intraperitoneal mouse virulence of Salmonella typhimurium hybrids expressing somatic antigen 9. Infect, Immun., 10 :669-671.

JOHNSON, W., 1973. Ribosomal vaccines. II - Specificity of the immune response to ribosomal ribonucleic acid and protein isolated from Salmonella typhimurium. Infect. Immun., $8: 395400$.

JOYEUX, Y.; JOUIN, H.; LELLUC, B. \& STAUB, A.M., 1974. Recherches sur l'antigène X responsable de la production des anticorps anti-Salmonella typhi, protecteurs pour l'embryon de poulet C.R. Acad. Sci (sér D), 279 :1507-1510.

JOYEUX, Y.; JOUIN, H.; LELUC, B. \& STAUB, A.M., 1977. Recherches sur l'antigène X responsable de la production des anticorps anti-Salmonella typhi, protecteurs pour l'embryon de poulet Ann. Immunol., $128: 221-223$.

KESSEL, R.W.I.; NETER, E. \& BRAUN, W., 1966. Biological activities of the common antigen of Enterobacteriaceae. J. Bacteriol. $91: 465-466$.

KIHLSTROM, E. \& EDEBO, L., 1976. Association of viable and inactivated Salmonella typhimurium 395 MS and MR 10 with HeLa cells. Infect. Immun., $14: 851-857$.

KLINE, B.C., 1976. Pili, plasmids, and microbial virulence. Mayo Clin. Proc. 51:3-12.

KRISHNAPILLAI, V. \& BARON, L.S., 1964. Alterations in the mouse virulence of Salmonella typhimurium by genetic recombination. J. Bacteriol., $87: 598-605$.

KUMATE, J.; CRAVIOTO, J.; HASHIMOTO, B.; VEGA, L. \& CARRILlO, J., 1971. Content of common antigen of Escherichia coli and diarrhea of newborns and infants in a Mexican pre industrial community. Ann. N.Y. Acad. Sci., $176: 350-359$.

KUNIN, C.M., 1962. Antibody distribution against nonenteropathic E. coli. Relation to age, sex and breast feeding. Arch. Intern. Med., $110: 676-686$.

KUNIN, C.M., 1963. Separation, characterization, and biologial significance of a common antigen in Enterobacteriaceae. J. Exp. Med., 118 :565-586.

KUNIN, C.M. \& BEARD, M.V., 1963. Serological studies of 0 antigens of Escherichia coli by means of the hemagglutination test. J. Bacteriol., $85: 541-548$.

KUNIN, C.M.; BEARD, M.V.; HALMAGYI, N.E., 1962. Evidence for a common hapten associated with endotoxin fraction of Escherichia coli and other Enterobacteriaceae. Proc. Soc. Exp. Biol. Med., $111: 160-166$. 
LAGERCRANTZ, R.; HAMMARSTROM, S.; PERLMANN， P. \& GUSTAFSSON, B.E., 1968. Immunological studies in ulcerative colitis. IV - Origin of autoantibodies. J. Exp. Med., 128 :1339-1352.

LANDY, M., 1952. Studies on Vi antigen. I - Relative Vi antigen content of V form cultures. Proc. Soc. Exp. Biol., 80 :55-58.

LANDY, M., 1953. Enhancement of the immunogenicity of typhoid vaccine by retention of the $\mathrm{Vi}$ antigen. Amer. J. Hyg., $58: 148-164$.

LANDY, A.; TRAPANI, R.J.; WEBSTER, M.E. \& JARVIS, F.G. 1963. Immunological properties of $\mathrm{Vi}$ isolated by chemical fractionation and by eletrophoresis. Tex. Rep. Biol. Med., 21 :214-229.

LEVIN, M.; WONG, K.H.; REYNOLDS, H.Y.; SUTTON, A. \& NORTHRUP, R.S., 1975. Vi antigen from Salmonella typhosa and immunity against typhoid fever. II - Safety and antigenicity in humans. Infect. Immun., 12 :1290-1294.

LUDERITZ, O.; STAUB, A.M. \& WESTPHAL, O., 1966. Immunochemistry of O and R antigens of Salmonella and related Enterobacteriaceae. Bacteriol. Rev., 30 :192-225.

LUDERITZ, O.;WESTPHAL, O.; STAUB, A.M. \& NIKAIDO, H., 1971. Bacterial endotoxins. Isolation and chemical and immunological characterization of bacterial lipopolysaccharides. In Microbial Toxins. Vol. 4, p. 145-224. WEINBAUM, G.; KADIS, S. \& AJL. S., Eds. Academic Pres Inc., New York.

LYMAN, M.B.; STEWARD, J.P. \& ROANTREE, R.J., 1976. Characterization of the virulence and antigenic structure of Salmonella typhimurium strains wiht lipopolysaccharide core defects. Infect. Immun., $13: 1539-1542$.

LYMAN, M.B.; STOCKER, B.A.D. \& ROANTREE, R.J., 1977. Comparison of the virulence of 0:9, 12 and $0: 4,5,12$ Salmonella typhinaurium hist transductants for mice. Infect. Immun., 15 $: 491-499$.

MAALOE, O., 1948. Pathogenic-apathogenic transformation of Salmonella typhimurium. Acta. Pathol. Microbiol. Scand. (Sect. B), $25: 414-430$.

MacKANESS, G.B.; BLANDEN, RV. \& COLLINS, F.M., 1966. Hostparasite relations in mouse typhoid. J. Exp. Med., $124: 373-583$.

MACKENZIE, G.M.; PIKE, R.M. \& SWINNEY, R.E., 1940. Virulence of Salmonella typhimurium. II Studies of the polysaccharide antigens of virulent and avirulent strains. J. Bacteriol., $40: 197-214$.

MAGNUSSON, K.E.; STENDHAL, O.; TAGESSON, C.; EDEBO, L. \& JOHANSSON, G., 1977. The tendency of smooth and rough Salmonella typhimurium bacteria and lipopolysaccharide to hydrophobic and ionic interaction, as studied in aqueous polymer two-phase systems. Acta Pathol., Microbiol. Scand. (Sect. B), 85 :212-218.

MAKELA, P.H. \& MAYER, H., 1976. Enterobacterial common antigen. Bacterial., Rev., 40 :591-632.

MAKELA, P.H.; VALTONEN, V.V. \& VALTONEN, M., 1973. Role of O-antigen (lipopolysaccharide) factors in the virulence of Salmonella. J. Infect. Dis. (Suppl.) $128: 81-85$.

MARCUS, S.; ESPLIN, D.W. \& DONALDSON, D.M., 1954. Lack of bactericidal effect of mouse serum on a number of common microorganisms. Science, $119: 877$.

MARGOLIS, J.M. \& BIGLEY, N.J., 1972. Cytophilic macroglobulin reactive with bacterial protein in mice immunized with ribonucleic acid-protein fractions of virulent Salmonella typhimurium. Infect. Immun., $6: 390-397$.

MARTIN, D.G.; JARVIS, F.G. \& MILNER, K.C., 1967. Physicochemical and biological properties of sonically treated Vi antigen. J. Bacteriol., $94: 1411-1416$.

MAYER, H. \& SCHMIDT, G., 1973. The occurrence of three different lipopolysaccharide cores in Shigella and their relationship to known enterobacterial core types. Zentralbl. Bakteriol. Parasitenked. Infecktionskr. Hyg. Abt. Orig. Reihe A, 224 :345-354. 
McCABE, W. R, 1972. Immunization with R mutants of $S$. minnesota. I - Protection against challenge with heterelogous Gram-negative bacilli. J. Immunol., $108: 601-610$.

McCABE, W.R., 1976. Immunoprophylaxis of Gram-negative bacillary infections. Ann. Rev. Med., 27 :335-341.

McCABE, W.R.; BRUINS, S.C.; CRAVEN, E. \& JOHNS, M., 1977. Cross-reactive antigens: their potential for immunization induced immunity to Gram-negative bacteria $J$. Infect. Dis. (Suppl.), $136: 161-166$.

MCCABE, W.R. \& GREELY, A., 1973. Common enterobacterial antigen. II - Effect of immunization on challenge with heterologous bacilli. Infect. Immun., 7 :386-392.

McCABE, W.R.; GREELY, A.; DiGENIO, T. \& JOHNS, M.A., 1973. Humoral immunity to type-specific and cross-reactive antigens of Gram-negative bacilli. J. Infect. Dis., (Suppl.) 128 :284-289.

McCABE, W.R.; JOHNS, M. \& DiGENIO, T., 1973. Common enterobacterial antigen. III - Initial titers and antibody response in bacteremia caused by Gram-negative bacilli. Infect. Immun., 7 :393-397.

McCABE, W.R.; KREGER, B.E. \& JOHNS, M.A., 1972. Type-specific and cross-reactive antibodies in Gram-negative bacteremia. N. Engl. J. Med. 287 :261-267.

McLAUGHLIN, J.C. \& DOMINGUE, G.L., 1974. The immunologic role of the ethanol-soluble enterobacterial common antigen versus experimental renal infection. Immunol. Commun., 3 :51-75.

MEDINA, S.; VAS, SI. \& ROBSON, H.G., 1975. Effect of nonspecific stimulation on the defense mechanism of inbred mice. J. Immunol., $114: 1720-1725$.

MILHOMEM, A.M., 1979. Contribuição ao estudo da imunidade na vacinação anti-tifoídica. Tese. Doutor em Ciências. Instituto de Microbiologia. U.F.R.J. Rio de Janeiro, 183p.

MILHOMEM, A.M. \& SUASSUNA, I., 1982. A imunidade na febre tifóide. I. A vacinação anti-tifóidica de Wright, 1896 a 1979. Mem. Inst. Oswaldo Cruz, 77 :93-120.

MILNER, K.C.; RUDBACH, J.A. \& RIBI, E., 1971. Bacterial endotoxins. General characteristics. In Microbial Toxins. Vol. 4, p. 1-65. WEIBAUM, G.; KADIS, S. \& AJL, S.J., eds. Academic Pres, Inc. New York.

MORGENSTERN, M.A. \& GORZYNSKI, E.A., 1973. Immune response of guinea pigs to commom enterobacterial antigen. Immunol. Commun., 2 :495-506.

MORGENSTERN, M.A. \& GORZYNSKI, E.A., 1977. Immunogenic cross-reactivity between human tissues and enterobacterial common antigen. Infect. Immun. $17: 36-42$.

MORRIS, J.A.; WRAY, C. \& SOJKA, W.L., 1976. The effect of T and B lymphocyte depletion on the protection of mice vaccinated with a gal E mutant of Salmonella typhimurium. Brit. J. Exp. Pathol, $57: 345-360$.

NAKANO, M. \& SAITO, K., 1969. Chemical components in the cell wall of Salmonella typhimurium effecting its virulence and immunogenicity in mice. Nature, $222: 1085-1096$.

NELSON, B.W. \& ROANTREE, R.J., 1967. Analysis of lipopolysaccharides extracted from penicillinresistant, serum-sensitive Salmonella mutants. J. Gen. Microbiol., 48 :179-188.

NETER, E., 1976. Factors of pathogenicity: Gram-negative bacteria. Zentralbl. Bakteriol. Parasitenkd. Infektionskr. Hyg. Abt. Orig. Reihe A, 235 :3-8.

NETER, E.; WHANG, H.Y.; SUZUKI. T. \& GORZYNSKI, E.A., 1964. Differences in antibody response of rabbit to intravenously injected soluble and cell attached enterobacterial antigen. Immunology, 7 :657-664. 
OSBORN, M.J.; GANDER, J.E. \& PARISI, E., 1972. Mechanism of assembly of the outer membrane of Salmonella typhimurium. Site of synthesis of lipopolysaccharide. J. Biol. Chem., 247 :3973-3986.

OSBORN, M.J. \& ROTHFIELD, L.J., 1971. Bacterial endotoxins. Biosynthesis of the core region of lipopolysaccharide. In Microbial Toxins. Vol. 4, p. 331-350. WEINSBAUM, G.S.; KADIS, S. \& AJL, S.J., eds. Academic Press Inc. New York.

PELUFFO, C.A., 1941. Stability of Vi antigen of Salmonella typhi. Proc. Soc. Exper. Biol. Med., 48 $: 340-343$.

PERLMANN, P.; HAMMARSTROM, S.; LAGERCRANTZ, R. \& GUSTAFSSON., B.E., 1965. Antigen from colon of germ free rats and antibodies in human ulcerative colitis. Ann. N.Y. Acad. Sci., 124 :377-394.

PERLMANN, P.; HAMMERSTROM, S.; LAGERCRANTZ, R. \& CAMPBELL, D., 1967. Autoantibodies to colon in rats and human ulcerative colitis: cross reactivity with Escherichia coli 014 antigen. Proc. Soc. Exp. Biol. Med., 125 :975-980.

PIKE, R.M. \& MACKENZIE, G.M., 1940. Virulence of Salmonella typhimurium. I - Analysis of experimental infection in mice with strains of high and low virulence. J. Bacteriol. $40: 171-195$.

RAFFEL, S., 1953. Immunity, hypersensitivity and serology, p. 419-426. Appleton-Century-Crofts, New York.

REYNOLDS, B.L. \& PRUUL, H., 1971. Protective role of smooth lipopolysaccharide in the serum bactericidal reaction. Infect. Immun., $4: 764-771$.

ROANTREE, R.J., 1960. Specific absorption of the complement dependent bactericidal effect of normal serum. Fed. Proc. $19: 204$

ROANTREE, R.J., 1967. Salmonella O antigens and virulence. Ann. Rev. Microbiol., 21 :443-466.

ROANTREE, R.J., 1971. Bacterial endotoxins. The relationship of lipopolysaccharide structure to bacterial virulence. In microbial toxins. Vol. 5, p. 1-37. WEINBAUM, G.; KADIS, S. \& AJL, S.J., eds. Academic Press Inc. New York.

ROANTREE, R.J. \& STEWARD, J.P., 1965. Mutations to penicilin resistance in the Enterobacteriaceae that affect sensitivity to serum and virulence for mouse. J. Bacteriol., $89: 630-639$.

ROWLEY, D., 1968. Sensitivity of rough Gram negative bacteria to the bactericidal action of serum. J. Bacteriol., 95 :1647-1650.

ROWLEY, D. \& JENKIN, C.R., 1962. Antigenic cross-reaction between host and parasite as a possible cau se of pathogenicity. Nature, $193: 151-154$.

SAITO, I., 1967. Sorological study of chronic pyelonephritis. Especially on the diagnostic value of the estimulation of enterobacterial common antibody response. Fukushima. J. Med. Sci., $14: 45-53$.

SAITO, I.; NAKANO, K.M.; AKIYAMA. T. \& USHIBA, D., 1962. Passive transfer of immunity to typhoid by macrophages. J. Bacteriol., $84: 500-507$.

SAN FORD, B.A.; THOMAS, V.L.; FORLAND, M.; CARSON, S. \& SHELOKOV, A., 1978. Immune response in urinary tract infection determined by radioimmunoassay and immunofluorescence: serum antibody levels against infecting bacterium and Enterobacteriaceae common antigen.J.Clin. Microbiol., 8 :575- 579.

SCHMIDT, G., 1973. Genetical studies on the lipopolysaccharide structure of Escherichia coli K-12. J. Gen. Microbiol., $77: 151-160$. 
SCHMIDT, G.; JANN, B. \& JANN, K., 1969. Immunochemistry of R lipopolysaccharides of Escherichia coli. Different core regions in the lipopolysaccharides of $\mathrm{O}$ grupo 8 Eur. J. Biochem., 10 :501-509.

SCHMIDT, G.; JANN, B. \& JANN, K., 1974. Genetic and immunochemical studies on Escherichia coli 014 K7: H -. Eur. J. Biochem., 42 :303-309.

SCHMIDT, G.; MANNEL, D.; MAYER, H.; WHANG, H.Y. \& NETER, E., 1976. Role of a lipopolysaccharides gene for immunogenicity of the enterobacterial common antigen. J. Bacteriol., 126 :579-586.

SCHUTZE, H., 1930. The importance of somatic antigen in the production of aertrycke and gartner immunity in mice. Brit. J. Exp. Pathol., $11: 34-42$.

SCHWARZ, M.M. \& COTRAN, R.S., 1973. Common enterobacterial antigen in human chronic pyelonephritis and interstitial nephritis. An immunofluorescent study. N. Engl. J. Med. $289: 830-835$.

SMITH, E.V.D., 1938. Heat stability and serological activity of toxic extracts of the typhoid bacillus. J. Infect. Dis. $63: 21-24$.

SMITH, H., 1977. Microbial surfaces in relation to pathogenicity. Bacteriol. Rev., 41 :475-500.

SMITH, R.A. \& BIGLEY, N.J., 1972a. Ribonucleic acid-protein fractions of virulent Salmonella typhimurium as protective immunogens. Infect. Immun., 6 :377-383.

SMITH, R.A. \& BIGLEY, N.J., 1972b. Detection of delayed hipersensitivity in mice injected with ribonucleic acid-protein in fractions of Salmonella typhimurium. Infect. Immun., $6: 384-386$.

SPAUN, J., 1957. Typhoid vaccine. Vi antigen and Vi antibody. Acta. Pathol. Microbriol. Scand (Suppl. B.) $123: 11-79$.

STANDFAST, A.F.B., 1960. A report on the laboratory assays carried out at the Lister Institute of Preventive Medicine on the typhoid vaccines used in the field study in Yugoslavia. Bull. W.H.O., $23: 37-45$.

STENDAHL, C. \& EDEBO, L., 1972. Phagocytosis of mutants of Salmonella typhimurium by rabbit polymorphonuclear cells. Acta. Pathol. Microbiol. Scand. (Sect. B.). $80: 481-488$.

STENDAHL, C.; TAGESSON, C.; MAGNUSSON, K.E. \& EDEBO, L., 1977. Physicochemical consequences of opsonization of Salmonella typhimurium with hyperimmune lgG complement. Immunology, $32: 11-18$.

STEWARD, J.P.; COLLINS, L.R. \& ROANTREE, R.J., 1966. Effects of immunization of guinea pigs lacking bactericidal antibody against Salmonella enteritidis. J. Immunol., 97 :224-234.

STEWARD, J.P. \& ROANTREE, R.J., 1961. Effect of mouse peritoneal fluid on strains of enteric bacilli. Proc. Soc. Exp. Biol. Med., 108 :654-658.

STJERNSTROM, I.; MAGNUSSON, K.E.; STENDAHL, O. \& TAGESSON, C., 1977. Liability to hydrophobic and charge interaction of smooth Salmonella typhimurium 395 MS sensitized with anti-MS immunoglobulin G and complement. Infect. Immun., 18 :261-265.

STOCKER, B.A.D. \& MAKELA, P.H., 1971. Bacterial endotoxins. Genetic aspect of biosynthesis and structure of Salmonella lipopolysaccharide. In Microbial Toxins. Vol. 4, p. 369-438. WEINBAUM, G.; KADIS, S. \& AJL, S., eds. Academic Press Inc., New York.

STUART, C.A., 1956. The unfortunate role of precedent in bacteriology. Bacteriol. Rev., 20 :203-206.

SUZUKI, T.; WHANG, H.Y. \& NETER, E., 1966. Studies of common antigen of Enterobacteriaceae with particular reference of Escherichia coli 014. Ann. Immunol Hung., 9 :283-292. 
TAGESSON, C. \& STENDAHL, O., 1973. Influence of the surface lipopolysaccharide structure of Salmonella typhimurium on resistance to in tracellular bactericidal systems. Acta. Path. Microbiol. Scand. (Sect. B.), $81: 473-480$.

TANNOCK, G.W.; BLUMERSHINE, R.V.H. \& SAVAGE, D.C., 1975. Association of Salmonella typhimurium with, and its invasion of the ileal mucosa in mice. Infect. Immun., $11: 365-370$.

THJфTTA, T.H. \& WAALER, E., 1932. Dissociation and sensitiveness to normal serum in dysentery bacilli of type III. J. Bacteriol., $24: 301-316$.

THOMSEN, O.F. \& HJORT, T., 1973. Immunofluorescent demonstration of bacterial antigen in experimental pyelonephrits with antiserum against common enterobacterial antigen. Acta. Path. Microbiol. Scand. (Sect. A), $81: 474-482$.

THOMSEN, O.F. \& HJORT, T., 1977. Antibodies against $E$. coli 0 -antigens and common enterobacterial antigen in kidneytransplant recipients. Acta. Path. Microbiol. Scand. (Sect. B.), 85:455461.

TOPLEY, W.W.C. \& AYRTON, J., 1924. Further investigations into the biological characteristics of B. enteritidis (Aertrycke) J. Hyg., $23: 198-222$.

TULLY, J.G. \& GAINES, S., 1961. H antigen of Salmonella typhosa. J. Bacteriol., 81 :924-932.

TULLY, J.G.; GAINES, S. \& TIGERTT, W.D., 1962. Attempts to induce typhoid fever in chimpanzees with non-Vi strains of Salmonella typhosa. J. Infect. Dis., $110: 47-54$.

TULLY, J.G.; GAINES, S. \& TIGERTT, W.D., 1963. Studies on infection and immunity in experimental typhoid fever. IV - Role of $\mathrm{H}$ antigen in protection. J. Infect. Dis., $112: 118-124$.

USHIBA, D., 1965. Two types of immunity in experimental typhoid; "cellular immunity" and "humoral immunity". Keio J. Med., $14: 45-61$.

VALTONEN, M.V.; LARINKARI, U.M.; PLOSILA, M.; VALTONEN, V.V. \& MAKELA, P.H., 1976. Effect of enterobacterial common antigen on mouse virulence of Salmonella typhimurium. Infect. Immun., $13: 1601-1605$.

VOLTONEN, M.V.; PlOSIlA, M.; VALTONEN, V.V. \& MAKELA, P.H., 1975. The quality of the lipopolysaccharide on mouse virulence of Salmonella enteritidis. Infect. Immun., 12 $: 828-832$.

VALTONEN, V.V., 1970. Mouse virulence of Salmonella strains: the effect of different smooth-type O side-chains. J. Gen. Microbiol., 64 :255-268.

VALTONEN, V.V.; AIRD, J.; VALTONEN, M.V.; MAKELA, O. \& MAKELA, P. H., 1971. Mouse virulence of Salmonella. Acta. Pathol. Microbiol. Scand. (Sect. B.), 79 :715-718.

VALTONEN, V.V. \& MAKELA, P.H., 1971. The effect of lipopolysaccharide modifications - antigenic factors 1, 5, 122 and 27 - on the virulence of Salmonella strains for mice. J. Gen. Microbiol., $69: 107-115$.

VENNEMAN, M.R., 1972. Purification of immunogenically active ribonucleic acid preparations of Salmonella typhimurium: molecular-sieve and anion-exchange chromatography. Infect. Immun., $5: 269-282$

VENNEMAN, M.R. \& BERRY, L.J., 1971a. Serum-mediated resistance induced with immunogenic preparations of Salmonella typhimurium. Infect. Immun., $4: 373-380$.

VENNEMAN, M.R. \& BERRY, L.J., 1971b. Cell-mediated resistance induced with immunogenic preparations of Salmonella typhimurium. Infect. Immun., 4 :381-387.

VENNEMAN, M.R.; BIGLEY, N.J. \& BERRY, L.J., 1970. Immunogenicity of ribonucleic acid preparations obtained form Salmonella typhimurium. Infect. Immun., 1 :574-582. 
VOSTI, K.L.; MONTO, A.S.; OLDER, J.J. \& PANTZ, L.A., 1964. The serological specificity of crude and purified antigen extracts of Escherichia coli hemagglutination reaction with rabbit and human antisera. J. Immunol. $93: 199-204$.

WAHDAN, M.H.; SIPPEL, J.E.; MIKHAIL, I.A.; RAHKA, A.E.; ANDERSON, E.S.; SPARKS, H.A. \& CVJETANOVIC, B., 1975. Controled field trial of a typhoid vaccine prepared with a nonmotile mutant of Salmonella typhi Ty2. Bull. W.H.O., $52: 69-73$.

WEBSTER, M.E.; LANDY, M. \& FREEMAN, M.E., 1952. Studies on Vi antigen. II - Purification of Vi antigen from Escherichia coli 5396/38. J. Immunol., $69: 135-142$.

WEBSTER, M.E.; SAGIN, J.F.; ANDERSON, P.R.; BREESE, S.S.; FREEMAN, M.G. \& LANDY, M., 1954. Studies on Vi antigen. IV-Phisicochemical characterization of Vi antigens isolated from V form Enterobacteriaceae. J. Immunol., 73 :16-22.

WHANG, H.Y. \& NETER, E., 1963. Study of heterogenetic (Kunin) antibodies in serum of healthy subjects and children with enteric and urinary tract infections. J. Pediat., $63: 412-419$.

WHANG, H.Y.; YAGI, Y. \& NETER, E., 1967. Characterization of rabbit antibodies against common bacterial antigen and their presence in the fetus. Intern. Arch. Allerg., 32 :353-365.

WONG, K.H. \& FEELEY, J.C., 1972. Isolation of Vi antigen and a simple method for its measurement. Appl. Microbiol., 24 :629-633.

WONG, K.H.; FEELEY, J.C.; NORTHRUP, R.S. \& FORLINES, M.E., 1974. Vi antigen from Salmonella typhosa and immunity against typhoid fever. I - Isolation and immunologic properties in animals. Infect. Immun., $9: 348-353$.

YOUMANS, A.S. \& YOUMANS, G.P., 1964. Nature of labile immunogenic substance in the particulate fractions isolated from Mycobacterium tuberculosis. J. Bacteriol., 88 :1030-1037.

YOUMANS, A.S. \& YOUMANS, G.P., 1965. Immunogenic activity of a ribosomal fraction obtained from Mycobacterium tuberculosis. J. Bacteriol., 89 :1291-1298.

YOUNG, L.S. \& STEVENS, P., 1977. Cross-protective immunity to Gram-negative bacilli: studies with core glycolipid of Salmonella minnesota and of Streptococcus pneumoniae. J.Infect. Dis. (Suppl.), $136: 174-180$.

ZINNER, S.H. \& McCABE, W.R., 1976. Effects of IgM and IgG antibody in patients with bacteremia due Gram-negative bacilli. J. Infect. Dis., 133 :37-45. 